\title{
EFEITO DA COMPACTAÇÃO E DA DESINFESTAÇÃO DO SOLO NO DESENVOLVIMENTO RADICULAR E NODULAÇÃO DA SOJA, INOCULADA OU NÃO COM Bradyrhizobium japonicum
}

\author{
ELOÁ VELASQUE SILVA BORGES \\ Engenheira Agrícola
}

Orientador: Dr. FRANCISCO LOMBARDI NETO

\begin{abstract}
Dissertação apresentada à Escola Superior de Agricultura "Luiz de Queiroz", Universidade de São Paulo, para obtenção do titulo de Mestre em Agronomia, Área de Concentração: Solos e Nutrição de Plantas.
\end{abstract}

PIRACICABA

Estado de São Paulo - Brasil

Junho 1997 
Dados Internacionais de Catalogação na Publicação (CIP) DIVISÃO DE BIBLIOTECA E DOCUMENTAÇÃO - Campus "Luiz de Queiroz"/USP

Borges, Eloá Velasque Silva

Efeito da compactação e da desinfestação do solo no desenvolvimento radicular e nodulação da soja, inoculada ou não com Bradyrhizobium japonicum / Eloá Velasque Silva Borges. - - Piracicaba, 1997.

$49 \mathrm{p}$.

Dissertação (mestrado) - - Escola Superior de Agricultura Luiz de Queiroz, 1997.

Bibliografia.

1. Compactação 2. Nodulação 3. Rizóbio 4. Soja 5. Solo I. Título

CDD 631.46

633.34 


\section{EFEITO DA COMPACTAÇÃO E DA DESINFESTAÇÃO DO SOLO NO DESENVOLVIMENTO RADICULAR E NODULAÇÃO DA SOJA, INOCULADA OU NÃO COM Bradyrhizobium japonicum}

\section{ELOÁ VELASQUE SILVA BORGES}

Aprovada em: 30/06/1997

Comissão julgadora:

Dr. Francisco Lombardi Neto

IAC/CAMPINAS

Prof $f^{a}$. Dra. Elke Jurandy Bran Nogueira Cardoso

ESALQ/USP

Prof. Dr. Gil Miguel de Souza Câmara

ESALQ/USP

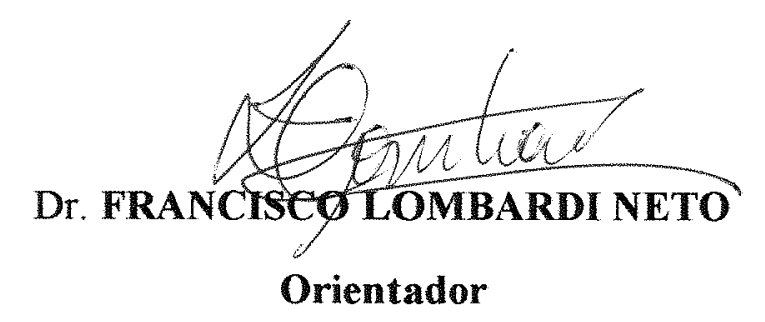




\section{DEDICATÓRIA}

A meu marido, Elias.

A minhas filhas Mariana e Ana Paula.

A meus pais, Dirceu e Zenith.

A meus irmãos Márcia, Kátia e Diógenes.

São eles a minha força de trabalho, minha felicidade e minha esperança. 


\title{
AGRADECIMENTOS
}

\author{
A Deus, por tudo.
}

Ao Dr. Francisco Lombardi Neto, pela orientação, pelo apoio e confiança.

A Dra. Maria Luiza C. O. Lombardi pelas sugestões e pelo incentivo. Aos professores Dra. Elke Jurandy Bran Nogueira Cardoso e Dr. Gil Miguel de Souza Câmara, pelas sugestões apresentadas.

A Escola Superior de Agricultura "Luiz de Queiroz" pela oportunidade de realização do Mestrado.

A Universidade Federal de Uberlândia pelo empréstimo da casa de vegetação e dos laboratórios para realização da pesquisa.

A Fundação Educacional de Ituiutaba por intermédio do seu ex-diretor Prof. Alan Kardec pelo apoio para realização do curso.

Ao Elias, pelo apoio, pela ajuda, pela força constante.

Aos meus queridos pais, grandes amigos, Dirceu e Zenith, razão da minha existência, por tudo.

As minhas filhas Mariana e Ana Paula, pela paciência por todos estes anos. Aos colegas Adriano Alves Pimenta, Manoel Ribeiro Pires, Daniel W. Bernardes, Eloisa M. Almeida Bernardes pelo auxílio na condução do trabalho em casa de vegetação.

Aos casais Hely e Ester, Benjamim e Mariannes que tanto me ajudaram.

Enfim, a todos aqueles que direta ou indiretamente, tenham contribuído para o êxito deste trabalho. 


\section{SUMÁRIO}

Páginas

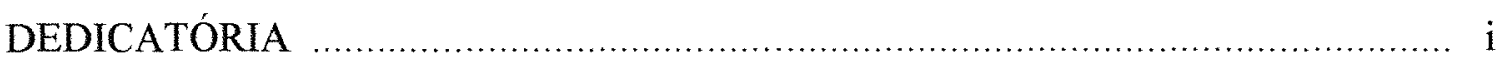

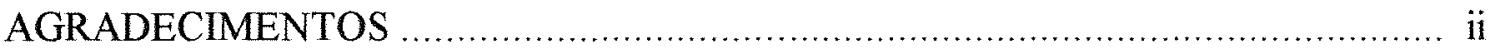

SUMÁRIO

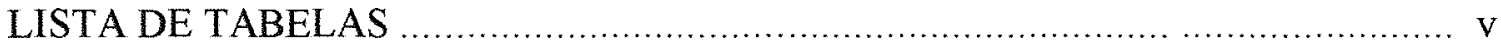

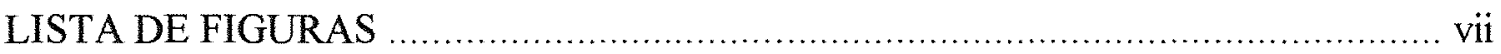

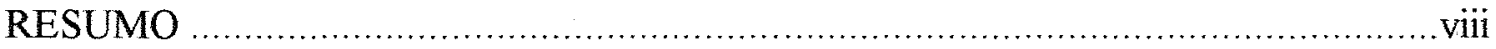

SUMMARY

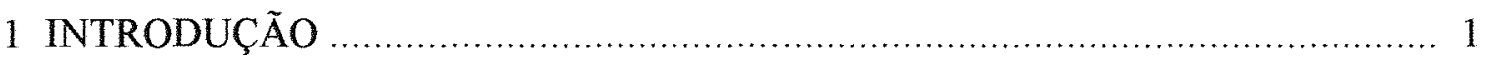

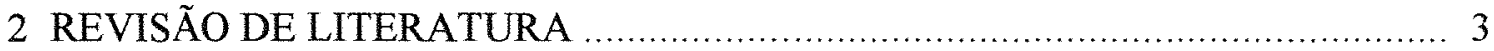

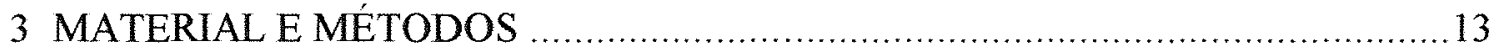

3.1 Local e época da condução do experimento ............................................... 13

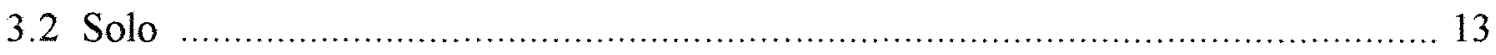

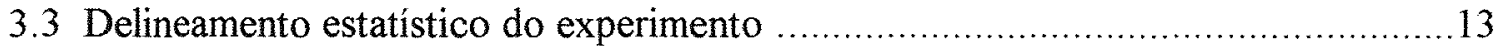

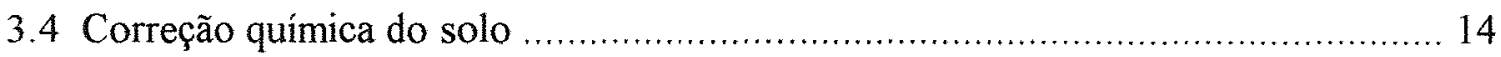

3.5 Tratamento químico do solo-desinfestação .......................................... 15

3.6 Aparelho compactador e coluna para compactação ................................... 15

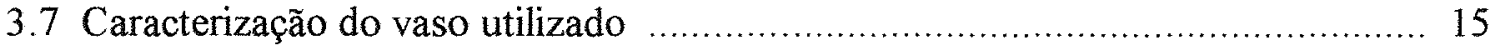

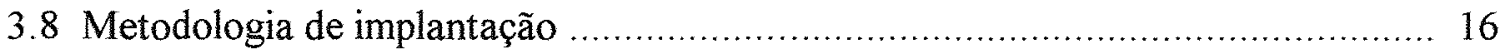

3.8.1 Estabelecimento dos tratamentos no anel superior ............................... 16

3.8.2 Estabelecimento dos tratamentos no anel central ................................... 16

3.8.3 Estabelecimento dos tratamentos no anel inferior ................................ 17

3.8.4 Esterelização e inoculação das sementes de soja ...................................... 18 


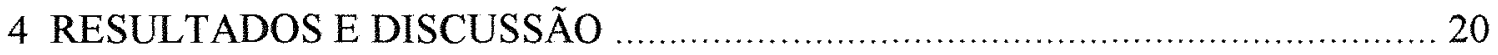

4.1 Produção de matéria seca da parte aérea da soja ...................................... 20

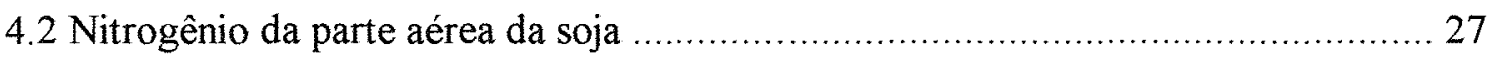

4.3 Produção de raízes no anel superior da coluna ........................................... 29

4.4 Massa dos nódulos do anel superior da coluna........................................... 34

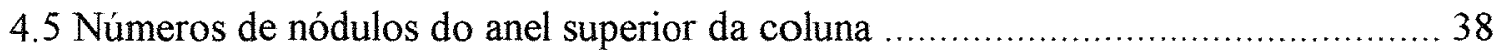

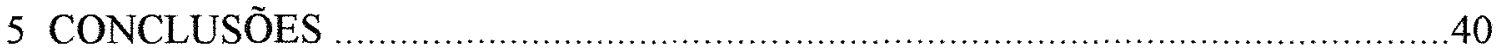

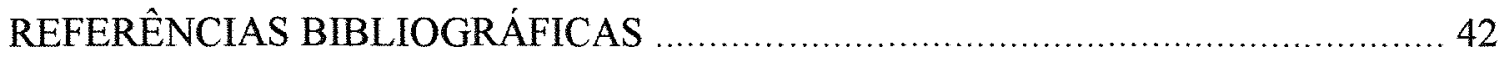




\section{LISTA DE TABELAS}

Páginas

1 Características físicas e químicas da amostra de solo da camada de $0-30 \mathrm{~cm}$, utilizado no experimento.

2 Concentrações e fontes dos elementos utilizados na adubação de base do solo

3 Produção de matéria seca da parte aérea em g, da soja, submetidas ao tratamento químico de solo, estirpes de rizóbios e diferentes níveis de compactação do solo do anel central

4 Resumo das analises de variância da produção de matéria seca da parte aérea (PMSPA) em g, concentração de nitrogênio na parte aérea (NPA) em \%, produção de raízes no anel superior (RAS) em g, massa (M.Nod) e números de nódulos $\left(\mathrm{N}^{0}\right.$ Nod) submetidas a tratamento químico de solo, inoculação de sementes com estirpes de rizóbios e diferentes níveis de compactação do solo do anel central.

5 Concentração de nitrogênio na parte aérea em \%, da soja, submetidas ao tratamento químico de solo, estirpes de rizóbios e diferentes níveis de compactação do solo.

6 Produção de raízes de soja, no anel superior da coluna, submetidas ao tratamento químico de solo, inoculação de sementes com estirpes de 
rizóbios e diferentes níveis de compactação do solo do anel central.......

7 Massa, em $\mathrm{g}$ anel ${ }^{-1}$, e número de nódulos das raízes de soja, coletadas no anel superior da coluna, submetidas ao tratamento químico de solo, com e sem inoculação de sementes, em diferentes níveis de compactação do solo do anel central. 


\section{LISTA DE FIGURAS}

Páginas

1 Esquema do vaso formado pela sobreposição de três anéis de PVC

2 Equações de regressão ajustadas para produção de massa seca da parte aérea da soja, em g, dentro de tratamento químico do solo e de estirpes de rizóbios, em função da densidade do solo do anel central da coluna $(X)$, em $\mathrm{kg} \mathrm{dm}^{-3}$

3 Equações de regressão ajustadas para produção de massa seca de raízes de soja, no anel superior da coluna, em g, dentro de tratamento químico do solo e de inoculação de estirpes de rizóbios, em função da densidade do solo do anel central da coluna, $(X)$, em $\mathrm{kg} \mathrm{dm}^{-3}$

4 Equações de regressão ajustadas para produção de massa seca de raízes de soja, no anel superior da coluna, em g, para cada estirpe de rizobio inoculado, dentro de tratamento químico do solo, em função da densidade do solo do anel central da coluna, $(X)$, em kg dm ${ }^{-3}$

5 Equações de regressão ajustadas para produção de massa seca de nódulos de rizóbios, no anel superior da coluna, em $\mathrm{g}$, dentro de tratamento químico do solo e de inoculação de estirpes de rizóbios, em função da densidade do solo do anel central da coluna $(\mathrm{X})$, em $\mathrm{kg} \mathrm{dm}^{-3}$ 
6 Equações de regressão ajustadas para número de nódulos de rizóbios, no anel superior da coluna, dentro de tratamento químico do solo e de inoculação de estirpes de rizóbios, em função da densidade do solo do anel central da coluna $(\mathrm{X})$, em kg dm ${ }^{-3}$ 


\section{EFEITO DA COMPACTAÇÃO E DA DESINFESTAÇÃO DO SOLO NO DESENVOLVIMENTO RADICULAR E NODULAÇÃO DA SOJA, INOCULADA \\ OU NÃO COM Bradyrhizobium japonicum}

Autora: Eloá Velasque Silva Borges

Orientador: Dr. Francisco Lombardi Neto

\section{RESUMO}

Estudou-se, em casa-de-vegetação, o efeito da desinfestação do solo com brometo de metila e da presença de camadas subsuperficiais compactadas no desenvolvimento das raízes e no estabelecimento da simbiose da soja com as estirpes nativa do solo, SEMIA 5079 e SEMIA 5080, inoculadas individualmente. Utilizou-se para tal, amostra de Latossolo Vermelho-Escuro álico, textura média, do município de Uberlândia, MG, previamente calcareado e adubado. Os vasos utilizados, foram formados pela sobreposição de três anéis de PVC, com $1,5 \mathrm{dm}$ de diâmetro e altura de $0,5 \mathrm{dm}$ para o anel central e inferior e 1,25 dm para o anel superior, unidos por fita adesiva.

O solo do anel central foi submetido a diferentes níveis de compactação para obter as densidades de: 1,$15 ; 1,30 ; 1,45 ; 1,60 \mathrm{~kg} \mathrm{dm}^{-3}$. Metade do solo utilizado foi previamente desinfestado, com $0,25 \mathrm{dm}^{3} \mathrm{~m}^{-3}$ de brometo de metila.

Formada a coluna, pela união dos três anéis com fita adesiva, foi plantada soja IAC8, com sementes previamente desinfestadas e inoculadas com as estirpes de rizóbios: SEMIA 5079 e SEMIA 5080. As estirpes nativas encontravam-se no solo utilizado. 
Quarenta e sete dias após a emergência, as plantas de soja foram cortadas rente ao solo, secadas em estufa de ventilação forçada, pesadas e submetidas à digestão para determinação do nitrogênio. As colunas de PVC foram desmontadas para coleta e quantificação de raízes e nódulos de rizóbios. Análise e interpretação dos dados possibilitaram constatar que a produção de matéria seca da parte aérea da soja foi crescente com a desinfestação do solo e inoculação com a estirpe de rizóbio SEMIA5080 , dentro das densidades de até $1,30 \mathrm{~kg} \mathrm{dm}^{-3}$. Para valores maiores do que este, as estirpes estudadas não diferiram entre si. A compactação, por outro lado, promoveu reduções lineares na produção de matéria seca da parte aérea no solo desinfestado, e, parabólica, com maior produção na densidade de $1,35 \mathrm{~kg} \mathrm{dm}^{-3}$ no solo não desinfestado.

A concentração de nitrogênio na parte aérea da soja foi significativamente menor com a inoculação da estirpe SEMIA 5079 no solo desinfestado, enquanto que, no não desinfestado as estirpes estudadas não diferiram entre si. A compactação aplicada reduziu linearmente a concentração de nitrogênio.

Com a desinfestação do solo a maior produção ocorreu com a presença da estirpe Nativa. Por outro lado, a compactação produziu efeito parabólico na produção de raízes tanto no solo desinfestado como no solo não desinfestado, com pontos de máxima produção nas densidades $1,43 \mathrm{~kg} \mathrm{dm}^{-3} \mathrm{e} 1,61 \mathrm{~kg} \mathrm{dm}^{-3}$ respectivamente.

A desinfestação do solo aumentou significativamente a massa dos nódulos em todos os níveis de compactação, enquanto que não houve efeito da estirpe inoculada. Por outro lado, a compactação promoveu aumentos da massa dos nódulos até a densidade do solo de $1,33 \mathrm{~kg} \mathrm{dm}^{-3}$ em todas as estirpes inoculadas.

Enquanto a desinfestação do solo possibilitou aumentos no número de nódulos, a inoculação não foi significativa. A compactação promoveu redução linear no número de nódulos no solo desinfestado e aumento linear no solo não desinfestado em todas as estirpes estudadas. 
EFFECT OF SOIL COMPACTION AND SOIL DESINFECTION ON ROOT DEVELOPMENT AND SOYBEAN NODULATION INOCULATED OR NOT WITH Bradyrhizobium japonicum

Author: Eloá Velasque Silva Borges Adviser: Dr. Francisco Lombardi Neto

\section{SUMMARY}

A greenhouse experiment was conducted to study the effects of subsoil compaction on root development and the establishment of soybean symbiosis with two native strains of bacteria ( SEMIA 5079 and SEMIA 5080) which were individually inoculated. A limed and fertilized medium textured Dark Red Latosol from Uberlandia, MG was used in the study. The pots for the study were constructed using three $1.5 \mathrm{dm}$ diameter PVC rings.

The middle and bottom rings were $0,5 \mathrm{dm}$ high and the top ring was $1.25 \mathrm{dm}$. High the rings were held together with adhesive tape. The soil in the middle ring was compacted to densities of $1.15,1.30,1.45$, and $1.60 \mathrm{~kg} \mathrm{dm}^{-3}$. The soil of one half of the pots was sterilized previously with $0,25 \mathrm{dm}^{3} \mathrm{~m}^{-3}$ of methyl bromide.

After the cylinder were taped together, IAC-8 soybean seed, which had been inoculated with the followring rhizobia strains: Native in the soil, SEMIA5079 and SEMIA5080, and they were planted. After 47 days of the germination. The plants were cut, oven-dried, weighed, digested, and analyzed for their nitrogen content. The PVC cylinders were then dismantled in order to collect and quantify root and nodule masses and 
numbers. The data indicated that shoot dry matter of soybean increased with the application of desinfection and with the inoculation of the strain SEMIA 5080, with soil densities up to $1.30 \mathrm{~kg} \mathrm{dm}^{-3}$. For greater densities, there was no difference between the two rhizobia strains.

There was a linear reduction in shoot dry matter with increasing compaction when no desinfection was applied. When the soil density was $1.35 \mathrm{~kg} \mathrm{dm}^{-3}$ there was a parabolic increase in dry matter mass due to the use of desinfection. Nitrogen concentration in the shoot was less when seeds were inoculated with SEMIA 5079 than for those inoculated with SEMIA 5080 when desinfection was applied, but there was no difference when desinfection was not applied.

Compaction linearly reduced nitrogen concentrations. Superficial root mass was greatest for soil not treated with desinfection and not inoculated with Rhizobia. The greatest root mass was recorded for soil treated with desinfection and seed inoculated with SEMIA 5079. Compaction of the soil linearly increased root production in soil which was not treated with desinfection. For soil compacted up to $1.43 \mathrm{~kg} \mathrm{dm}$, root production increased parabolically when desinfection was applied.

Desinfection significantly increased nodulation for all levels of compaction, but there was no effect from the different strains of rhizobia. On the other hand, compaction up to $1.33 \mathrm{~kg} \mathrm{dm}^{-3}$ promoted increases in nodule weight in plants inoculated with either strain of Bradyrhizobium. Treatment with desinfection tended to increase nodulation but the difference was not significant. Increasing compaction resulted in a linear reduction in the number of nodules in desinfected soil and a linear increase in soil not treated with bromide, regardless of the Rhizobium strain. 


\section{INTRODUÇÃo}

Com raras exceções, o Brasil tem aumentado sua produção agrícola, nas últimas décadas pela expansão da área cultivada, utilizando-se para isso os solos de cerrado. A escolha dessa fronteira agrícola deve-se à sua situação geográfica privilegiada, em relação aos grandes centros consumidores e/ou exportadores e à existência de pesquisas em fertilidade do solo e nutrição de plantas capazes de tornarem estes solos produtivos.

Com as condições físicas do solo favoráveis, topografia plana, novas tecnologias geradas pela pesquisa e programas de créditos governamentais, os solos sob vegetação de cerrado deixaram de ser utilizados com pecuária extensiva e agricultura de subsistência para uma exploração agrícola moderna, tecnificada e empresarial, principalmente para culturas de exportação.

A busca de ganhos de produtividade, principalmente na cultura da soja, tem sido perseguida mediante emprego de tecnologia sofisticada.

Práticas de manejo tais como preparo do solo, adubações e calagens intensivas, algumas vezes executadas de modo incorreto, ocasionam alterações fisicas do solo, com reflexos nas propriedades físicas, químicas, fisico-químicas e atividades biológicas (Carvalho Jr., 1995). Segundo Sumner (1992), alterações na disponibilidade de nutrientes, provocadas pela calagem e adubações químicas pesadas, têm contribuído para a dispersão de argila com conseqüente movimento vertical. A deposição dessa argila entre 20 - $30 \mathrm{~cm}$ de profundidade proporciona a formação de uma camada compactada que, além de restringir a infiltração de água e o crescimento de raízes, provoca a formação de um ambiente redutor com produção de elementos tóxicos (Vomocil \& Flocker, 1961). Estas condições, atuam sobre a população microbiana do solo, seja por proporcionar menor desenvolvimento radicular da planta, portanto com menor substrato para a 
atividade biológica ou indiretamente através de estímulos seletivos negativos (Nuiernberg, 1983).

Além da compactação do solo, o sistema convencional de preparo do solo promove diferentes graus de mobilização, alterando em curto espaço de tempo as taxas de aeração, umidade e disponibilidade de nutrientes. Tais alterações podem propiciar condições desfavoráveis à simbiose, seja por inibir os rizóbios ou por impedir o desenvolvimento das raízes. A exploração agrícola de solos com leguminosas fixadoras de nitrogênio, prática comum no cerrado, principalmente com a cultura da soja, irá demandar estudos mais detalhados sobre quais atributos fisicos e químicos do solo irão afetar o processo e a eficiência da simbiose.

Dentro desse contexto, a seleção de estirpes de rizóbios adaptados, com boa capacidade de fixação de nitrogênio em condições de solos compactados, onde o excesso de $\mathrm{CO}_{2}$, a defíciência de $\mathrm{O}_{2}$, bem como a presença de elementos tóxicos produzidos pelo ambiente redutor devem ser pesquisados, principalmente para as culturas de expressão econômica como as produtoras de grãos.

Segundo Vargas et al. (1992), a estirpe SEMIA 5079 foi selecionada pelo método de Peres et al. (1984), de um solo quimicamente pobre do Distrito Federal, e pertence ao mesmo sorogrupo da SEMIA 566, enquanto que a SEMIA 5080 foi obtida através de uma subcultura de SEMIA 586. Estes pesquisadores afirmam ainda que estas duas estirpes têm sido testadas há mais de sete anos nos solos de cerrado, onde promoveram ganhos de rendimentos de até $750 \mathrm{~kg} \mathrm{ha}^{-1}$, em solos de primeiro cultivo, em relação ao tratamento sem inoculação.

Diante do exposto, esta pesquisa teve por objetivos:

a) Verificar o efeito de camadas subsuperficiais compactadas no desenvolvimento das raízes e no estabelecimento da simbiose da soja, com as estirpes nativa, SEMIA 5079 e SEMIA 5080, inoculadas individualmente.

b) Estimar a absorção e concentração de nitrogênio em plantas de soja noduladas em ambiente compactado. 


\section{REVISÃO DE LITERATURA}

Os solos sob vegetação de cerrado em uso e potencialmente agricultáveis, compreendem uma área estimada em 207 milhões de hectares, incluindo diferentes classes de solos (Macedo, 1996). Segundo Lopes (1984) estes solos apresentam como características químicas, baixos valores de $\mathrm{pH}, \mathrm{Ca}, \mathrm{Mg}$ e $\mathrm{P}$ e altos teores de alumínio e/ou manganês e como características físicas, alta porosidade e baixa densidade. $\mathrm{O}$ uso prolongado desses solos, num sistema de manejo avançado, proporciona sua recuperação química, mas torna-os fisicamente deteriorados. Segundo Carvalho Jr. (1995) é comum a formação de uma camada subsuperficial compactada e/ou adensada.

O uso intensivo atual, de grandes partes desses solos, continua sendo feito de forma inadequada, conforme observam Freitas (1994). A degradação do solo, ou o melhoramento de seu potencial produtivo é função do manejo a que é submetido. Como componente básico dos ecossistemas terrestres, o recurso solo, também está, sujeito a variações nos demais componentes, tais como a hidrologia e os organismos, que por sua vez, estão sujeitos aos efeitos da ação antrópica. (Melo Filho \& Silva, 1993).

O efeito de sistemas de uso e manejo sobre propriedades físicas do solo tem sido temas de várias pesquisas (Anjos et al., 1994; Bertol, 1994; Carvalho Jr. 1995; Melo Filho \& Silva 1993; Pimentel \& Chaves, 1993), abrangendo diferentes ecossistemas.

As conclusões encontradas neste estudo comprometem, particularmente na camada arável, as qualidades fisicas, principalmente aquelas que decorrem da porosidade efetiva (permeabilidade ao ar, drenagem, água disponível, erodiblidade, densidade aparente, consistência, espaço para crescimento radicular) e, consequentemente, o funcionamento destes solos para produções agrícola satisfatórias. Este comprometimento da estrutura, tem sido constatado em maior ou menor grau, em diversos sistemas de 
manejo, em diferentes classes de solos dentro dos chamados solos de cerrado (Bertol, 1994; Melo Filho \& Silva, 1993; Reichert et al., 1993).

Com relação ao solo, em seu estado natural, tem sido verificado o aumento da densidade, devido à compactação, dificultando as trocas gasosas, a infiltração e o movimento de água, o crescimento de raízes, a atividade de microrganismos decompositores e/ou fixadores de nitrogênio, conforme enfatizam Borges et al. (1997) e Freitas (1994).

Alvarenga (1993) e Costa (1979) comentam que o espaço poroso de aeração (macroporosidade efetiva) não deve ficar aquém de 10 a $12 \%$ do volume do solo, para que o crescimento de raízes e de microrganismos não seja comprometido.

Segundo Sanchez (1981) a compactação no geral pode aumentar a quantidade de água contida na faixa de disponibilidade para as plantas, por aumentar os poros de retenção. Entretanto Stone et al. (1994) afirmam que este aumento pode não ocorrer, como observaram em um latossolo vermelho-escuro argiloso, após sete anos de cultivos sucessivos sob pivô central com arroz e feijão. Nestas condições, observaram que na camada de 0 a $20 \mathrm{~cm}$ a água disponível diminui de $10,6 \mathrm{~mm}$ para $8,0 \mathrm{~mm}$, enquanto que, na camada de 20 a $40 \mathrm{~cm}$ o decréscimo foi de 9,0 para $7,2 \mathrm{~mm}$, com a evolução da compactação do solo. Tardieu (1988) citado por Camargo \& Alleoni (1997) afirma que sintomas de estresse hídrico aparecem em solos compactados devido ao arranjamento compacto das raízes em pequeno volume do solo, como observado com a cultura de milho, onde o comprimento das raízes por unidade de volume de solo foi cerca de vinte vezes menor na entrelinha compactada de um solo franco argiloso do que na linha e na entre linha não compactada.

Em um solo compactado ocorre diminuição na porosidade livre de água, com conseqüente decréscimo em sua permeabilidade tanto da água como das trocas gasosas. A baixa aeração induz à ramificação das raizes adventícias superficiais, tornandoas menos eficientes na absorção de água nutrientes e trocas gasosas, conforme afirmam (Camargo \& Alleoni, 1997).

Borges (1995), ao promover a compactação do solo, elevando os valores de densidade de $1,32 \mathrm{~kg} \mathrm{dm}^{-3}$ para $1,77 \mathrm{~kg} \mathrm{dm}^{-3}$ em um Latossolo Vermelho-Escuro 
textura média, observou que a porosidade total de $51,39 \%$, distribuída em $17,7 \%$ para a retenção de água e $33,69 \%$ para trocas gasosas, foi reduzida para $34,27 \%$. Desse total, $22,9 \%$ eram destinados à retenção de água e 11,3\% destinados a aeração. Percebe-se então, que a compactação reduziu a aeração em aproximadamente três vezes, enquanto que a umidade volumétrica foi aumentada em 1,58 vezes, comprometendo o crescimento das plantas e dos microrganismos.

Dentro desse contexto, Eaves et al. (1969) comentam que entre 10 e 15\% de aeração do solo pode não ocorrer crescimento de plantas e microorganismos aeróbios.

Embora a compactação possa provocar grandes restrições às trocas gasosas entre o solo e a atmosfera, podendo causar, em curtos espaços de tempo, danos irreparáveis ao sistema radicular e conseqüentemente ao desenvolvimento da nodulação, alguns trabalhos de campo demonstram que sob determinados níveis de compactação a composição gasosa do solo não é drasticamente afetada. Revisando as relações existentes entre o espaço poroso ocupado pelo ar e pela água, Vomocil e Flocker (1961) verificaram que um pequeno movimento de ar ainda ocorre no solo quando a porosidade é reduzida em $90 \%$, sendo, no entanto, considerado limitante ao desenvolvimento de raizes e microorganismo aeróbios.

Uma redução no espaço aéreo, abaixo do mínimo necessário, para o crescimento de raízes e certamente para nodulação da soja foi observado por Cintra \& Mielniczuck (1983) quando a densidade do solo era superior a $1,30 \mathrm{~kg} \mathrm{dm}^{-3}$. Isso ocasionou $50 \%$ de redução no comprimento das raízes da soja. Esses autores observaram ainda que esta cultura respondeu positivamente à compactação até a densidade de $1,40 \mathrm{~kg}$ $\mathrm{dm}^{-3}$, graças a um melhor arranjamento das partículas, melhor retenção de água e nutrientes.

Grable \& Siemer (1968) afirmam que valores elevados de densidade do solo, por meio da compactação, podem inibir tanto o crescimento radicular como a macro e microfauna do solo. Segundo Taylor \& Gardner (1963) isto ocorre em virtude do aumento do número de pequenos poros e consequentemente da diminuição dos macroporos. Pouco aproveitamento da água da chuva ou da irrigação, com constante saturação do perfil, causando danos às raízes por condições de redução química, toxidez 
de ferro e/ou manganês, menor transporte de nutrientes em direção às raizes são algumas das conseqüências advindas da compactação que terão reflexos no crescimento radicular e na nodulação em leguminosas.

Grable (1966) e Camargo (1983) mostram que um desbalanceamento da relação água/oxigênio/gás carbônico, pode induzir a produção de substâncias tóxicas para os vegetais, alterações no $\mathrm{pH}$ e na disponibilidade de nutrientes. Como esta relação é dependente da porosidade, alterando-a com a compactação, modifica-se também o ambiente próximo às raízes.

Cassel (1991) observou que em latossolo roxo sob cultivo convencional há mais de 15 anos, a compactação do solo reduziu a porosidade de aeração para valores menores do que $0,10 \mathrm{~m}^{3} \mathrm{~m}^{-3}$, valor este muito inferior ao mínimo necessário para a atividade biológica das raízes e dos microrganismo. Segundo Cintra et al. (1983), a aeração mínima está em torno de $0,19 \mathrm{~m}^{3} \mathrm{~m}^{-3}$.

Camargo \& Alleoni (1997) afirmam que o fluxo de calor ou a condutividade térmica do solo são diretamente proporcionais ao estado de compactação do solo. Segundo estes pesquisadores, a variação da densidade do solo de $1,06 \mathrm{~kg} \mathrm{dm}^{-3}$ para $1,59 \mathrm{~kg} \mathrm{dm}^{-3}$ acarretou aumentos em $40 \%$ da difusividade térmica em um solo argiloso. Nas condições tropicais, com maior incidência solar sobre a superficie, esta situação pode criar condições desfavoráveis às atividades biológicas das plantas e microrganismos do solo, como enfatizado por Sanchez (1981).

Camargo \& Alleoni (1997) afirmam que a compactação do solo pode predispor o ambiente a algumas injúrias do sistema radicular e aos microrganismos do solo, devido ao aumento da persistência de herbicidas, fungicidas ou inseticidas, favorecendo inclusive maior severidade das doenças da parte subterrânea da planta. Moots et al. (1988) observaram que a podridão de raízes e o número de plantas mortas aumentaram com a compactação do solo.

Para que o cultivo da soja, ou de qualquer outra leguminosa, inclusive aquelas destinadas a recuperar o solo, possa ser feita economicamente, é desejável que os rizóbios utilizados, encontrem condições favoráveis para o estabelecimento de uma simbiose eficiente. 
A disponibilidade de nutrientes no solo é também afetada pela compactação, já que os mecanismos de fluxo de massa e difusão, responsáveis pelo transporte de nutrientes até aos sítios de absorção, são processos dependentes da estrutura do solo. Revisando este assunto, Bacchi (1976) cita que, além de modificar os mecanismos pelos quais os nutrientes são transportados no solo, a compactação pode alterar a quantidade de nutrientes disponiveis na medida em que altera a mineralização de compostos orgânicos por afetar a aeração e a umidade do solo, tão importantes para a atividade microbiana do solo.

Voorhees (1977) observou que o trigo cultivado na presença de camadas compactadas apresentava maior estresse hídrico. Segundo o autor, a compactação aumenta o conteúdo volumétrico de água, mas não aumenta sua disponibilidade para as plantas e organismos vivos do solo. Tal fato deve-se à quebra de continuidade dos poros que trazem a água das camadas inferiores para a superficie e a maior força de retenção da água pelos finos poros produzidos pela compactação, de maneira geral não explorados pelas raízes e organismos do solo.

Grable (1966) afirma que a interação entre compactação e atributos físicos do solo é complexa, e, possivelmente torna-se mais ainda quando a planta e os microorganismos como rizóbios fazem parte desse ambiente. Nesse particular o pesquisador sugere que nenhuma predição deve ser feita entre densidade do solo e parâmetros químicos e físicos do solo, uma vez que ambos são variáveis com o solo, manejo, exigência dos rizóbios e das plantas.

Espera-se que a seleção de estirpes adaptadas à presença de camadas compactadas possam melhor estabelecer e proporcionar uma nodulação satisfatória, uma vez que a capacidade de infeccionar, multiplicar e colonizar a superficie da raiz além de ser intrínseca do microsimbionte depende das características fisicas e químicas do solo (Franco \& Vincent, 1976).

Tratando-se de leguminosas para adubação verde, a presença de rizóbios no solo compactado é uma característica importante para garantir a simbiose, proporcionando maior produção de massa vegetal para incorporação ao solo. A restrição ao desenvolvimento radicular poderá dificultar ou mesmo inibir o estabelecimento da 
simbiose, pois, para ocorrência da associação há necessidade de se ter a planta como fornecedora de foto-assimilados para que a bactéria seja capaz de formar os nódulos, o que não acontece quando a planta se encontra em extremos de desnutrição (Munns, 1965).

A inoculação de leguminosas como soja é uma prática importante, que visa o estabelecimento da simbiose planta/rizóbios, que resulta em maior produtividade do hospedeiro, com menor custo de produção, representando uma redução de até um quarto nos custos.

Segundo Hungria et al. (1994) a instalação do processo simbiótico pode ser dividida em quatro fases: a) multiplicação da bactéria na rizosfera; b) infecção da planta e formação dos nódulos; c) atividade do nódulo e d) crescimento da planta e senescência dos nódulos.

Estas quatro fases do estabelecimento do processo simbiótico, bem como sua eficiência em fixar nitrogênio são influenciadas pelas condições do ambiente físico e químico do solo, carga genética da planta e da bactéria.

A eficiência da nodulação varia com o hospedeiro e mesmo com o tipo de solo. Vargas \& Suhet (1980) observaram, em condições de campo, que o cultivar de soja IAC-2 apresentou melhor comportamento quando inoculada com a estirpe SEMIA 5019. Em outro solo de cerrado, já com presença de camadas compactadas, a estirpe SEMIA 965 superou a SEMIA 5019, com a mesma cultivar IAC - 2 (EMBRAPA-CPAC, 1979a). Esses resultados concordam com as observações anteriores, de que a distribuição de diferentes estirpes de rizóbios e sua capacidade de induzir nodulação no hospedeiro, quando inoculados individualmente ou em mistura, é variável de solo para solo (Han et al., 1971; Norris, 1965).

Desse modo, Peres \& Vidor (1980), encontraram diferenças no comportamento de seis estirpes aplicadas isoladamente e/ou em mistura em soja cultivada em areia e solo. Todas as estirpes foram eficientes na fixação de nitrogênio nas plantas cultivadas em areia, enquanto que nas cultivadas em solo as estirpes SEMIA 527 e SEMIA 532 foram ineficientes. É possível que essas diferenças possam ser atribuídas a fatores fisicos como aeração, trocas gasosas e ambiente redutor. 
Meade at al. (1985) e Triplett \& Sadwsky (1992), afirmam que muitos dos casos de insucessos da nodulação são atribuídos à baixa competitividade das estirpes de bactérias inoculadas, que não são capazes de prevalecer nos nódulos do hospedeiro, principalmente quando o solo apresenta condições químicas e físicas desfavoráveis.

Johnson et al. (1965) salientam que o êxito de estirpes de rizóbios introduzidas como inóculo vai depender, além de sua capacidade de competir por sítios de infecção, das características do solo. Por outro lado, Bohlool \& Schmidt (1973) demonstraram que estirpes menos eficientes na fixação de nitrogênio e menos competitivas podem predominar em anos subseqüentes à inoculação, demonstrando claramente que outros fatores do solo possivelmente estão envolvidos no desempenho de determinadas estirpes como inóculo.

A ocorrência em larga escala de camadas compactadas ou adensadas subsuperficiais ( $2-3 \mathrm{dm})$, além da restrição mecânica imposta ao crescimento de raízes, poderá apresentar restrição de natureza química como elevada acidez, altos teores de $\mathrm{Mn}$ e à baixa disponibilidade de bases e fósforo, uma vez que, estas camadas se formam abaixo da camada de incorporação de insumos agrícolas, que, de maneira geral são de baixa movimentação no perfil do solo (Carvalho Jr., 1995).

Segundo Cattelan \& Hungria (1994), as plantas que fixam nitrogênio, portanto as que tem condições de formar simbiose com os rizóbios são mais exigentes em fertilidade do solo, pois requerem os nutrientes necessários ao hospedeiro, ao rizóbio e ao sistema simbiótico. Para a maioria das estirpes, a exigência em $\mathrm{pH}$ para o crescimento do Rizóbios em condições controladas relaciona-se bem com as exigências do hospedeiro (Munns, 1977).

Asanuma \& Ayanaba (1990); Franco \& Dobereiner (1971); Taylor et al. (1991) afirmam que a acidez afeta principalmente o estádio de infecção, devido à redução da atividade das enzimas relacionadas com a quebra da parede celular. A acidez também prejudica a sobrevivência do rizóbio, por diminuir a disponibilidade de cálcio, magnésio, molibdênio e fósforo e aumentando a de alumínio e manganês.

Contudo, redução linear na velocidade de crescimento das raízes foi observado por Phillips \& Kirkhan (1962) quando a densidade variou de 0,94 para 1,30 kg 
$\mathrm{dm}^{-3}$. Nessas condições, o comprimento das raizes decresceu de 52 para $10 \mathrm{~cm}$. Certamente, esta redução no comprimento das raizes poderá provocar redução na taxa absorção de nutrientes, principalmente o nitrogênio, se estruturas especiais como os rizóbios não estiverem associadas.

Garcia-Blasquez et al. (1991) observaram que a fixação de nitrogênio foi significativamente superior nos tratamentos que receberam irrigação em relação aos tratamentos não irrigados. Sprent (1976), afirma que a inoculação em condições de déficit hídrico induz alterações estruturais e fisiológicas nos nódulos. Esses autores verificaram que quando a umidade do nódulo cai para valores inferiores a $80 \%$, há uma diminuição sensivel na atividade da nitrogenase, chegando a ocorrer desintegração do nódulo.

$\mathrm{O}$ estudo de nodulação e eficiência da simbiose na presença de camadas subsuperficiais compactadas é escassos ou inexistentes. Marcos Filho (1986) afirma que a deficiência hídrica provocada por qualquer situação durante o período vegetativo provoca reduções no desenvolvimento radicular, na taxa de crescimento, na atividade fotossintética, na fixação de $\mathrm{N}_{2}$ e no metabolismo da planta, com redução no aproveitamento dos nutrientes do solo, prejudicando não só a fixação simbiótica mas a cultura que é exigente em nutrientes.

Garcia-Blasquez et al. (1991) observaram que a quantidade de $\mathrm{N}$ total da soja para todos os tratamentos inoculados foi maior sob condições irrigadas, confirmando a importância da pronta disponibilidade de água para o crescimento da planta e para uma boa nodulação. Estes pesquisadores comentam ainda que a falta ou excesso de água, além de prejudicar diretamente o desenvolvimento da cultura, afeta o processo de fixação biológica de $\mathrm{N}$, influenciando as atividades fisiológicas dos microorganismo bem como sua sobrevivência. Por outro lado a fixação de $\mathrm{N}_{2}$ pode ser totalmente inibida em condições de saturação de água o que parece estar relacionado com a capacidade das células dos rizóbios suportar as modificações físico/químicas e biológicas causadas pelas condições de anaerobiose.

Além da redução da água prontamente disponível, Borges et al. (1988) verificaram que as raízes desenvolvidas em solos compactados apresentam alterações morfológicas como raizes curtas, grossas, escamosas e espessas. Estas características 
poderão constituir um impedimento ao estabelecimento da nodulação. Estes pesquisadores observaram ainda que a presença da compactação subsuperficial induz as plantas a concentrarem suas raizes na camada superficial do solo. Tratando-se de planta que desenvolve nodulação como a soja, esta concentração de raízes na superfície pode não ser desejável uma vez que, nas condições tropicais é comum a temperatura da camada superficial atingir 40 a 50 , graus podendo inibir o desenvolvimento e a eficiência dos rizóbios.

Malavolta (1972) afirma que a incorporação de matéria orgânica verde ou decomposta aumenta sensivelmente a produção das leguminosas, devido à melhoria dos atributos físicos do solo, ativando a microflora que por sua vez pode aumentar a disponibilidade de nutrientes.

Ruschel \& Saito (1977) estudando a influência da matéria orgânica na nodulação em Phaseolus vulgaris verificaram aumento no peso dos nódulos, indicando que a matéria orgânica provavelmente proporciona melhores condições fisicas do solo para o estabelecimento das bactérias fixadoras de $\mathrm{N}_{2}$. Estes pesquisadores encontraram que além do maior peso dos nódulos os teores de $\mathrm{N}$ total na parte aérea eram positivamente correlacionados com a adição de matéria orgânica. Foi observado ainda neste experimento que nos tratamentos que receberam adubação orgânica houve estímulo para nodulação de plantas não inoculadas, sugerindo que o desenvolvimento da nodulação nativa do solo pode ser estimulada pela melhoria das propriedades fisicas e químicas do solo.

Hale et al.(1978) afirmam que a rizosfera, desde que equilibrada fisicamente, é caraterizada pela capacidade de estimular a multiplicação de microorganismos entre os quais os rizóbios, já que os exsudatos radiculares possuem, além de efeito na melhoria da estrutura do solo, efeito nutricional para multiplicação dessas bactérias.

Segundo Lovato et al. (1985) o comportamento das diferentes estirpes de rizóbios no solo é afetado por fatores físicos e químicos do solo. Estes pesquisadores, estudando a densidade populacional de rizóbios na rizosfera interna e externa das raízes das plantas, observaram que o declínio da população era maior na rizosfera externa. 
Redução da comunidade dos rizóbios à medida que se afastava da rizosfera deve-se possivelmente à ausência de exsudato das raízes e ao ambiente físico do solo não ser adequado à multiplicação dos rizóbios. Estes pesquisadores observaram ainda que a relação rizóbios interno x rizóbios externo na rizosfera aumentou com o tempo indicando que a população aumenta com a idade da planta. Isto pode ser devido à melhoria do ambiente físico e de matéria orgânica produzida pelo sistema radicular, bem como à senescência dos nódulos, com liberação e multiplicação de bactérias na rizosfera. 


\section{MATERIAL E MÉTODOS}

\subsection{Local e época da condução do experimento}

O experimento foi conduzido no Campus da Universidade Federal de Uberlândia, em casa de vegetação pertencente ao Departamento de Agronomia, no período de 20 de julho a 10 de novembro de 1996.

\subsection{Solo}

A amostra de solo utilizado foi coletada na camada de $0-3,0 \mathrm{dm}$ de um Latossolo Vermelho-Escuro Álico, A moderado textura média, fase cerrado tropical subcaducifólio, relevo suave ondulado, situado na Fazenda Experimental Água Limpa da Universidade Federal de Uberlândia- Uberlândia/MG, sem uso agrícola.

Esta classe de solo ocorre no Triângulo Mineiro sob o clima Aw da classificação de Köppen, representa aproximadamente $58 \%$ dos solos da região (EMBRAPA/SNLCS, 1982), cujos atributos físicos e químicos foram caracterizados conforme metodologia preconizada pela EMBRAPA/SNLCS (EMBRAPA, 1979b) (Tabela 1).

\subsection{Delineamento estatístico do experimento}

O delineamento estatístico utilizado foi um fatorial $2 \times 3 \times 4$ distribuído ao acaso, com quatro repetições, correspondendo respectivamente a dois tratamentos químicos do solo (com brometo e sem brometo), três estirpes de rizóbios (Nativa do solo, 
SEMIA 5079 e SEMIA 5080) e a quatro níveis de compactação quantificados pelas densidades do solo: $1,15 \mathrm{~kg} \mathrm{dm}^{-3}$ (normal); $1,30 \mathrm{~kg} \mathrm{dm}^{-3} ; 1,45 \mathrm{~kg} \mathrm{dm}^{-3}$ e $1,60 \mathrm{~kg} \mathrm{dm}^{-3}$ aplicadas no anel intermediário de uma coluna constituída pela sobreposição de três anéis de PVC.

Tabela 1. Características físicas e químicas da amostra de solo da camada de $0-3,0 \mathrm{dm}$, utilizado no experimento.

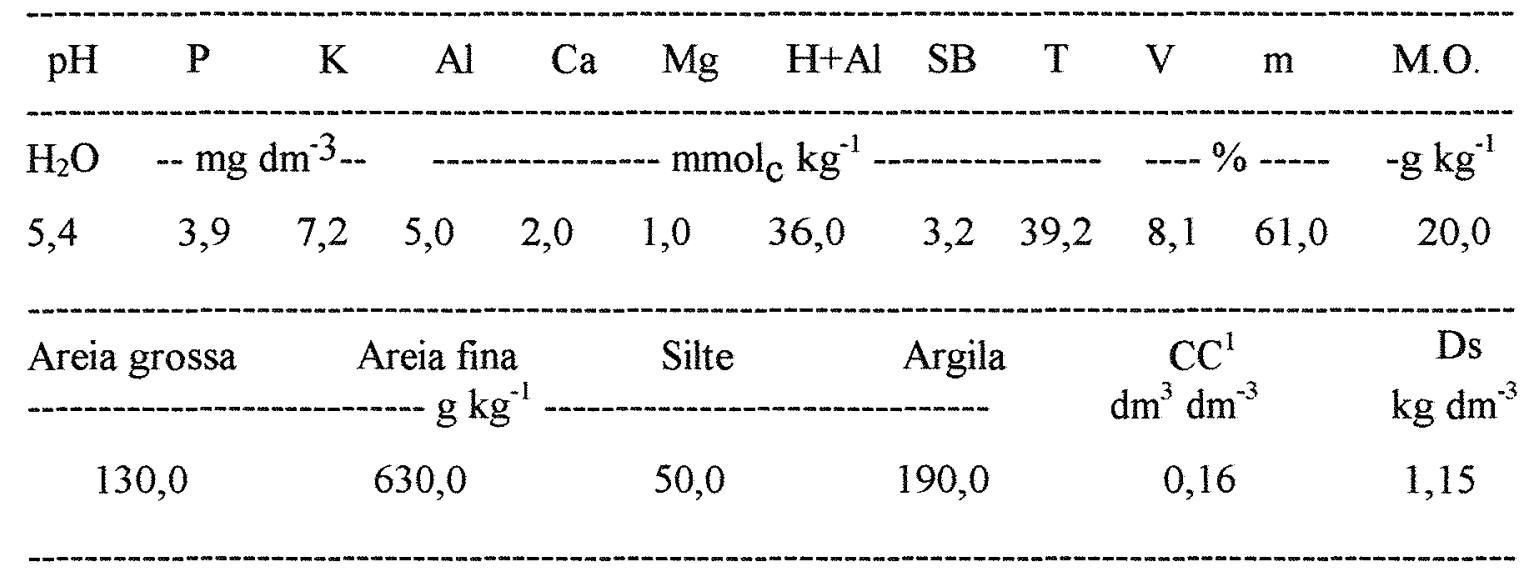

${ }^{1}$ Conforme COSTA (1983)

As análises estatísticas dos resultados constaram da análises de variância, segundo delineamento em blocos casualizados. Foi utilizado o teste de Tukey a $5 \%$ para comparação entre médias dos tratamentos e regressões com coeficientes de determinação (r) testados pelo teste $t$ a $5 \%$ de probabilidade, utilizando-se o programa estatístico SANEST.

\subsection{Correção química do solo}

Foi feita calagem para correção da acidez, aplicando-se calcário, constituído pela mistura carbonato de cálcio + carbonato de magnésio P.A., na relação estequiométrica $4: 1$, em dose equivalente a $3,0 \mathrm{t} \mathrm{ha}^{-1}$, tomando-se como base para cálculo da necessidade de calagem o método de saturação de bases (Raij et. al., 1985). Seguiu-se um período de incubação de aproximadamente 50 dias, sendo a umidade mantida próxima a $80 \%$ da capacidade de campo, determinada conforme Costa (1983). Após estabilização 
do $\mathrm{pH}$, o material de solo foi novamente seco ao ar e passado em peneira de $0,02 \mathrm{dm}$ para receber a adubação de base (Tabela 2).

\subsection{Tratamento químico do solo - desinfestação}

Após estabilização do $\mathrm{pH}$, metade da amostra de solo $(150 \mathrm{~kg})$ foi depositada em uma caixa d'água, capacidade de $1000 \mathrm{~L}$, para ser submetido a desinfestação. Para tal, utilizou-se o gás brometo de metila na quantidade de $0,25 \mathrm{dm}^{3} \mathrm{~m}^{-3}$ de solo. Para aplicação do gás vedou-se completamente a caixa com plástico preto deixando-o dessa maneira por um período de 10 dias , com posterior ventilação (CollozziFilho \& Balota, 1994).

\subsection{Aparelho compactador e coluna para compactação}

Para efetuar a compactação do solo foi utilizada prensa hidráulica, capacidade de 50 toneladas, tendo um disco de ferro de diâmetro igual ao do anel $(1,5$ dm) acoplado à cabeça do hidráulico. O recipiente utilizado para compactação foi um anel cilíndrico de PVC de $0,5 \mathrm{dm}$ de altura e 1,5 dm de diâmetro.

Durante a compactação o anel de PVC foi introduzido no interior de um protetor, com chapa de ferro de $0,1 \mathrm{dm}$ de espessura, e formato de meia cana, para aumentar a resistência do anel de $\mathrm{PVC}$ à deformação ou à ruptura quando submetido à carga da prensa hidráulica.

\subsection{Caracterização do vaso utilizado}

Cada vaso, capacidade de aproximadamente $3,53 \mathrm{dm}^{3}$, foi constituído pela sobreposição de três anéis de PVC de 1,5 dm de diâmetro e altura de 1,25 dm para o anel superior, sendo $0,25 \mathrm{dm}$ destinados a retenção da irrigação e $0,5 \mathrm{dm}$ para os anéis intermediário e inferior, unidos por fita adesiva após a aplicação dos tratamentos. O fundo do vaso foi vedado por uma placa de isopor perfurada (Figura 1). 


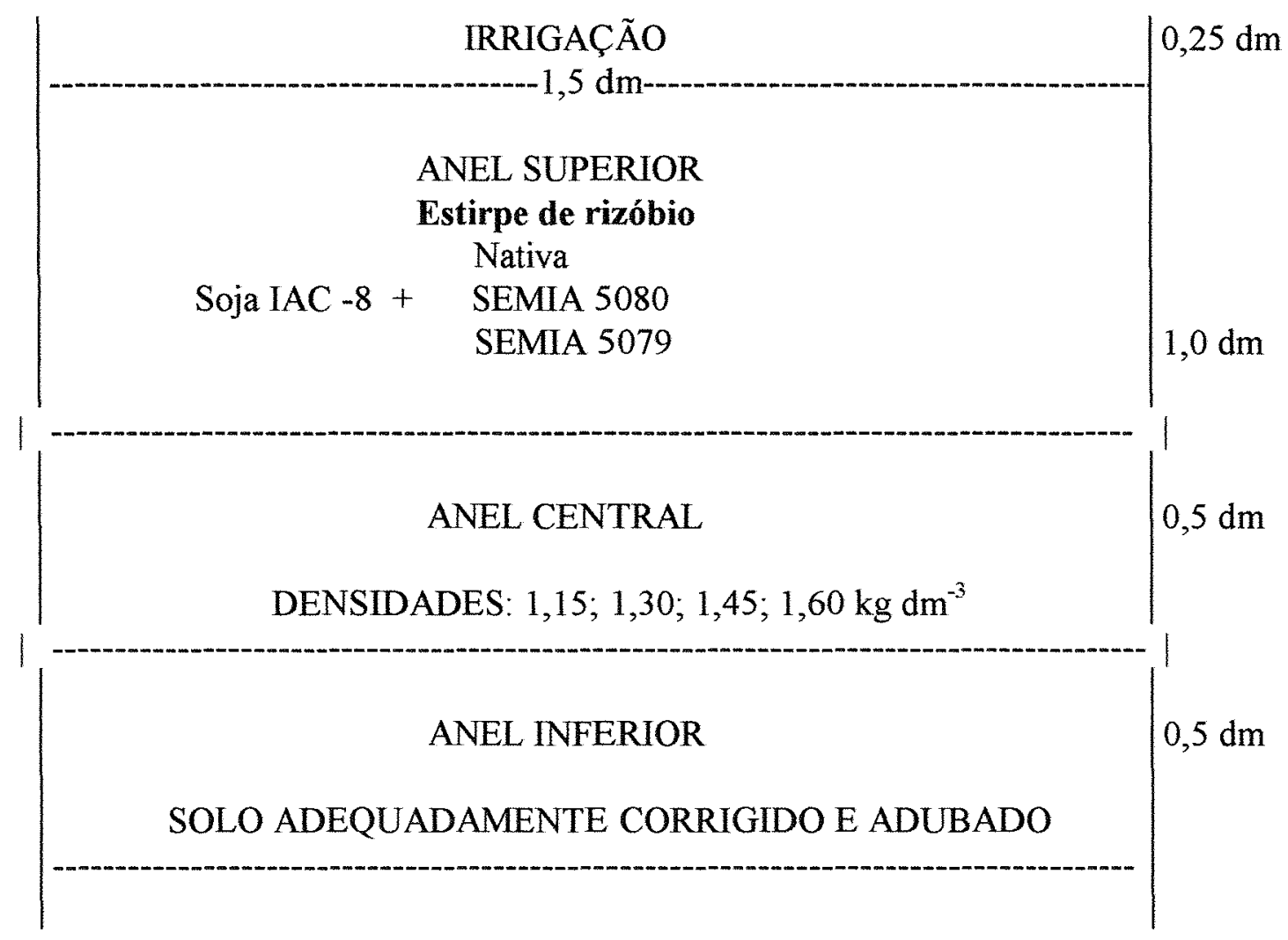

Figura 1- Esquema do vaso formado pela sobreposição de três anéis de PVC.

\subsection{Metodologia de implantação}

\subsubsection{Estabelecimento dos tratamentos no anel superior}

Em todas as colunas, o primeiro anel $(0,25-1,25 \mathrm{dm}$ de altura a partir do ápice), com capacidade para $1,77 \mathrm{dm}^{3}$, recebeu solo corrigido e adubado com $0,048 \mathrm{dm}^{3}$ da solução estoque (Tabela 2).

\subsubsection{Estabelecimento dos tratamentos no anel central}

$\mathrm{O}$ anel central $(1,25-1,75 \mathrm{dm})$ recebeu diferentes quantidades de solo, com objetivo de obterem-se as densidades: $1,15 \mathrm{~kg} \mathrm{dm}^{-3}$ (normal); $1,30 \mathrm{~kg} \mathrm{dm}^{-3} ; 1,45 \mathrm{~kg} \mathrm{dm}^{-3}$ e $1,60 \mathrm{~kg}$ $\mathrm{dm}^{-3}$. 
Tabela 2. Concentrações e fontes dos elementos utilizados na adubação de base do solo.

\begin{tabular}{llc}
\hline Elemento & \multicolumn{1}{c}{ Fontes } & $\begin{array}{c}\text { Quantidade de Reagente/10 1 } \\
\text { (solução estoque) }\end{array}$ \\
\hline $\mathrm{P}$ & $\mathrm{NaH}_{2} \mathrm{PO}_{4}$ & $50,0 \mathrm{~g}$ \\
$\mathrm{~K}$ & $\mathrm{KH}_{2} \mathrm{PO}_{4}$ & $150,0 \mathrm{~g}$ \\
$\mathrm{~S}$ & $\mathrm{KH}_{2} \mathrm{PO}_{4}$ & - \\
$\mathrm{S}$ & $\mathrm{CuSO}_{4} \cdot 5 \mathrm{H}_{2} \mathrm{O}$ & $1,10 \mathrm{~g}$ \\
$\mathrm{Fe}$ & $\mathrm{ZnSO}_{4} \cdot 7 \mathrm{H}_{2} \mathrm{O}$ & $586,5 \mathrm{mg}$ \\
$\mathrm{Mn}$ & $\mathrm{FeCl}_{3} \cdot 6 \mathrm{H}_{2} \mathrm{O}$ & $252,05 \mathrm{mg}$ \\
$\mathrm{Cu}$ & $\mathrm{MnCl}_{2} \cdot 4 \mathrm{H}_{2} \mathrm{O}$ & $4,39 \mathrm{~g}$ \\
$\mathrm{Zn}$ & $\mathrm{CuSO}_{4} \cdot 5 \mathrm{H}_{2} \mathrm{O}$ & - \\
$\mathrm{B}$ & $\mathrm{ZnSO}_{4} \cdot 7 \mathrm{H}_{2} \mathrm{O}$ & $16,82 \mathrm{mg}$ \\
\hline $\mathrm{H}_{3} \mathrm{BO}_{3}$ & $1,56 \mathrm{~g}$ \\
\hline
\end{tabular}

A compactação do solo, quantificada pela densidade e aplicada somente no anel central de cada coluna, foi obtida fixando-se o volume do anel em $0,88 \mathrm{dm}^{3} \mathrm{e}$ determinando-se previamente a quantidade de solo seco ao ar com $6,8 \mathrm{dm}^{3} \mathrm{dm}^{-3} \mathrm{de}$ umidade base em peso $(1,084 ; 1,225 ; 1,367$ e $1,508 \mathrm{~kg})$ necessárias para alcançar os diferentes valores de densidades. Cada sub-amostra a ser compactada, recebeu $0,033 \mathrm{dm}^{3}$ $\mathrm{kg}^{-1}$ da solução estoque da Tabela 2 e foi em seguida umedecida até atingir $60 \%$ da sua capacidade de campo. Mediante o uso de uma prensa hidráulica, foram aplicadas as cargas necessárias para alcançar os diferentes níveis de compactação desejado.

\subsubsection{Estabelecimento dos tratamentos no anel inferior}

Este anel, com capacidade de $0,88 \mathrm{dm}^{3}(0,5 \mathrm{dm}$ de altura e $1,5 \mathrm{dm}$ de diâmetro), recebeu $1 \mathrm{dm}^{3}$ de solo, previamente adubado com $0,033 \mathrm{dm}^{3} \mathrm{~kg}^{-1}$ da solução estoque da tabela Tabela 2. 


\subsubsection{Esterilização e Inoculação das sementes de soja}

As sementes de soja, cultivar IAC-8, provenientes do Banco de Sementes do Departamento de Agronomia da UFU, com poder germinativo de $80 \%$, foram submetidas a tratamentos distintos:

As sementes utilizadas no plantio dos vasos cujo solo foi submetido ao tratamento com o gás brometo, foram desinfestadas com solução de hipoclorito de sódio comercial na concentração de $2,5 \%$, diluída em uma proporção de uma parte de hipoclorito para duas partes de água, onde permaneceram por 5 minutos. Em seguidas foram lavadas com água destilada e esterilizada em autoclave por aproximadamente 6 vezes.

A presença de bacterias fixadoras de nitrogênio foi garantida através das estirpes naturalmente presentes no solo (nativa) e pela inoculação com inoculante turfoso, cedido pelo Centro de Pesquisas de Fixação Biológica do Nitrogênio (CPFBN) FEPAGRO/MIRCEM - Porto Alegre, RS contendo as estirpes SEMIA 5079 e SEMIA 5080 , numa quantidade equivalente de $600 \mathrm{~g}$ do inoculante para $50 \mathrm{~kg}$ de sementes. Para garantir uma adequada aderência do inóculo junto à superficie da semente foi utilizada uma solução de sacarose a $15 \%$ (Hungria et al., 1994).

Uma vez efetuada a compactação do solo no anel central, este foi unido por fita adesiva a um anel superior de $1,77 \mathrm{dm}^{3}$ e a outro inferior de $0,88 \mathrm{dm}^{3}$ contendo solo previamente adubado e homogeneizado e vedado ao fundo com uma placa de isopor perfurada.

Cada vaso assim constituído, foi semeado com seis sementes de soja, previamente inoculadas com as estirpes de rizóbios estudadas. Aos 11 dias do plantio fezse o desbaste, reduzindo a três plantas por vaso.

A irrigação das plantas foi feita com água destilada, por meio de pesagem dos vasos, com a finalidade de manter a umidade com $80 \%$ da capacidade de retenção de água do solo.

Aos 47 dias da emergência, as plantas foram cortadas rentes ao solo, secas em estufa de ventilação forçada a $65^{\circ} \mathrm{C}$ até massa constante, pesadas e moídas para à 
análise do nitrogênio. As colunas foram desmontadas para análise da nodulação no anel superior, que consistiu na contagem e pesagem dos nódulos secos em estufa com ventilação forçada a $65^{\circ} \mathrm{C}$ por um período de 48 horas. As raízes do anel superior foram coletadas, lavadas e colocadas para secar para obtenção da massa de matéria seca. 


\section{RESULTADOS E DISCUSSÃO}

\subsection{Produção de matéria seca da parte aérea da soja}

Os dados de produção de matéria seca da parte aérea da soja, em função dos tratamentos de desinfestação do solo, estirpes de rizóbios e níveis de compactação (Tabela 3) foram submetidos à análise de variância (Tabela 4), teste de Tukey (Tabela 3) e análise de regressão (Figura 2). Constataram efeitos significativos para os tratamentos principais (tratamento químico do solo, inoculação de estirpes de rizóbios e níveis de compactação) bem como para as interações: tratamento químico do solo $\mathrm{x}$ níveis de compactação; estirpe de rizóbios $\mathrm{x}$ níveis de compactação, possibilitando que cada tratamento envolvido nas interações significativas fosse estudado dentro dos níveis do outro e vice-versa.

Ausência de significância para interação tratamento do solo $x$ estirpes de rizóbios possibilitou que estes efeitos fossem estudados com a média de 12 observações. Neste caso, observa-se que a produção de matéria seca da parte aérea foi significativamente maior na condição de solo com brometo (Tabela 3).

Considerando o efeito dos tratamentos químicos do solo dentro de cada nível de compactação observa-se (Tabela 3) que a desinfestação possibilitou maior produção de matéria seca da parte aérea em todos os níveis de compactação realizadas no anel central da coluna, conforme teste Tukey aplicado às médias com 12 repetições com $5 \%$ de probabilidade. Possivelmente, a desinfestação do solo tenha proporcionado maior persistência e maior condição para competição saprofitica no solo, tanto da estirpe Nativa como das inoculadas, mesmo naqueles ambientes redutores, produzidos pelos níveis mais elevados de compactação. 
Tabela 3. Produção de matéria seca da parte aérea em g da soja, submetidas ao tratamento químico de solo, estirpes de rizóbios e diferentes níveis de compactação do solo do anel central

\begin{tabular}{|c|c|c|c|c|c|}
\hline \multirow{2}{*}{$\begin{array}{l}\text { Densidade } \\
\left(\mathrm{Kg} \mathrm{dm}^{-3}\right)\end{array}$} & \multirow{2}{*}{$\begin{array}{c}\text { Tratamento } \\
\text { Químico }\end{array}$} & \multicolumn{3}{|c|}{ Estirpes de Rizóbios } & \multirow[b]{2}{*}{ médias } \\
\hline & & Nativa & SEMIA5079 & SEMIA 5080 & \\
\hline \multirow{4}{*}{$\begin{array}{c}1,15 \\
\text { médias }\end{array}$} & Com Brometo & 12,300 & 10,976 & 13,236 & $12,171 \mathrm{a}$ \\
\hline & Sem Brometo. & 7,428 & 7,070 & 10,348 & $8,282 b$ \\
\hline & & $9,864 \mathrm{~B}$ & $9,023 \mathrm{~B}$ & $11,792 \mathrm{~A}$ & \\
\hline & Com Brometo & 10,837 & 10,997 & 12,565 & $11,466 \mathrm{a}$ \\
\hline 1,30 & Sem Brometo. & 8,922 & 8,444 & 9,300 & $8,889 \mathrm{~b}$ \\
\hline \multirow[t]{2}{*}{ médias } & & $9,879 \mathrm{~B}$ & $9,721 \mathrm{~B}$ & $10,932 \mathrm{~A}$ & \\
\hline & Com Brometo & 9,939 & 9,587 & 10,424 & 9,983a \\
\hline 1,45 & Sem Brometo & 8,941 & 8,737 & 8,806 & $8,828 \mathrm{~b}$ \\
\hline \multirow[t]{2}{*}{ médias } & & $9,440 \mathrm{~A}$ & $9,162 A$ & $9,615 \mathrm{~A}$ & \\
\hline & Com Brometo & 10,202 & 9,460 & 9,677 & $9,780 \mathrm{a}$ \\
\hline 1,60 & Sem Brometo. & 7,400 & 8,077 & 8,321 & $7,932 \mathrm{~b}$ \\
\hline médias & & $8,801 \mathrm{~A}$ & $8,769 \mathrm{~A}$ & $8,999 A$ & \\
\hline
\end{tabular}

- Médias seguidas por letras minúsculas distintas, na coluna, diferem entre si a $5 \%$ de probabilidade pelo teste de Tukey.

- Médias seguidas por letras maiúsculas distintas, na linha, diferem entre si a $5 \%$ de probabilidade pelo teste de Tukey.

Dentro deste contexto, (EMBRAPA-CPAC, 1982) afirma que a capacidade de competição saprofitica bem como a persistência no solo de estirpes usadas nos inoculantes é também importante quando se considera a possibilidade de introduzi-la no 
ano anterior ao plantio via inoculação de sementes de cereais. Essa prática tem sido proposta como alternativa para melhorar o estabelecimento de determinadas estirpes mais eficientes na fixação de nitrogênio em condições desfavoráveis à colonização imediata dos rizóbios.

Analisando o comportamento de cada estirpe de rizóbio dentro de cada nível de compactação verifica-se (Tabela 3) que na densidade do solo de $1,15 \mathrm{~kg} \mathrm{dm}^{-3}$ (sem compactação) e densidade de $1,30 \mathrm{~kg} \mathrm{dm}^{-3}$ (leve compactação) a estirpe SEMIA 5080 possibilitou produção de matéria seca da parte aérea significativamente maior do que as estirpes nativas e a SEMIA 5079, as quais não diferiram entre si. Níveis de compactação efetuados para obter densidades maiores do que $1,30 \mathrm{~kg} \mathrm{dm}^{-3}$ não promoveram diferenças significativas entre as três estirpes de rizóbios conforme consta da Tabela 3.

Segundo Johnson et al. (1965) o êxito das estirpes de rizóbios introduzidas como inoculantes vai depender, além de sua capacidade de competir por sítios de infecção, das características físicas do solo. Por outro lado, Bohlool \& Schmidt (1973) demonstraram que estirpes menos eficientes na fixação de nitrogênio e menos competitivas podem predominar em anos subseqüentes à inoculação, demonstrando claramente que outros fatores do solo possivelmente estão envolvidos no desempenho de determinadas estirpes como inóculo.

Regressões ajustadas (Figura 2) possibilitam verificar que produção de matéria seca da parte aérea $(Y)$ foi linearmente decrescente com os níveis de compactação aplicados no anel central da coluna quando o solo foi submetido ao brometo de metila.

Quando o solo não foi desinfestado, o comportamento da equação utilizada para descrever a produção de matéria seca da parte aérea em função dos níveis de compactação foi quadrática, com ponto de maior produção de raízes na densidade do solo de $1,35 \mathrm{~kg} \mathrm{dm}^{-3}$. Produção crescente da parte aérea com aumento da densidade do solo até este ponto de máximo, no solo sem brometo, mostra a importância tanto dos atributos físicos desejáveis do solo como da atividade microbiana na melhoria do ambiente radicular. 


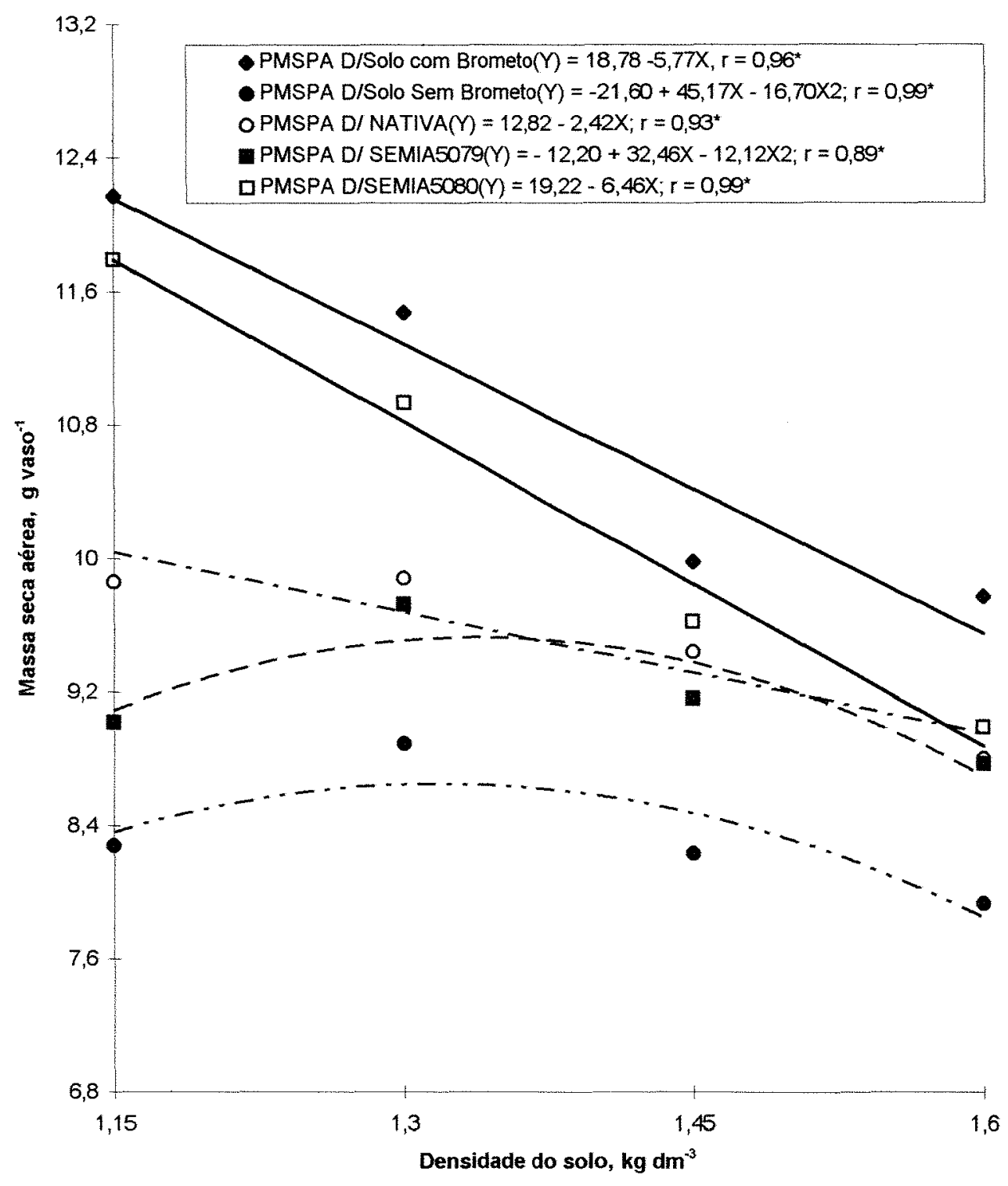

Figura 2. Equações de regressão ajustadas para produção de massa seca da parte aérea da soja, em $\mathrm{g}$, dentro de tratamento químico do solo e de estirpes de rizóbios, em função da densidade do solo do anel central da coluna $(X)$, em kg dm${ }^{-3}$ 
O efeito da compactação na produção vegetal tem sido relatado por diversos pesquisadores, mas ainda existem muitas divergências. Alguns têm observado que uma leve compactação pode provocar aumento de crescimento na parte aérea. Outros, no entanto, têm encontrado que o efeito da compactação do solo na parte aérea da planta é depressivo em todos os seus níveis, a partir da condição natural. Borges et al. (1987) e Borges et al. (1988), trabalhando com cinco variedades de soja e três espécie de eucalipto, encontraram que o efeito da compactação na produção de matéria seca da parte aérea podia variar com a espécie vegetal. Estes autores verificaram que as variedades de soja IAC-8, Bossier e Cristalina apresentavam comportamento quadrático para a produção de matéria seca da parte aérea, quando o solo era compactado. Entretanto, as variedades Tropical e Doko tiveram produção sempre decrescente a partir do nível zero de compactação.

Conclusões semelhantes a esta foram obtidas por Rosemberg (1964), após estudar o efeito da compactação no rendimento das culturas de milho, tomate, batata, beterraba e algodão. Este autor observou que, enquanto a beterraba e algumas variedades de batata apresentavam redução linear na produção, o milho, o tomate e o algodão apresentavam comportamento quadrático com pontos de máximo para uma leve compactação. Tal comportamento foi atribuído ao tipo de sistema radicular. Se a planta possui um sistema radicular pivotante, o crescimento das raizes em solo compactado torna-se mais dificil por possuir quase sempre diâmetro maior do que os poros do solo. O mesmo não acontece com as raízes tipo fasciculada que são geralmente mais finas. Como a soja possui raízes pivotantes, é possível que as densidades de 1,45 e $1,60 \mathrm{~kg} \mathrm{dm}^{-3}$ reduziram o diâmetro dos poros para um tamanho menor o que as raizes seriam capazes de explorar. 
Tabela 4. Resumo das análises de variância da produção de matéria seca da parte aérea (PMSPA) em g, concentração de nitrogênio na parte aérea (NPA) em \%, produção de raízes no anel superior (RAS) em g, massa (M. Nod) e números de nódulos $\left(\mathrm{N}^{\circ}\right.$. Nod) submetidas ao tratamento químico de solo, inoculação de sementes com estirpes de rizóbios e diferentes níveis de compactação do solo do anel central.

\begin{tabular}{|c|c|c|c|c|c|c|}
\hline \multirow[b]{2}{*}{ FONTE DE VARIAÇÃO } & \multirow[b]{2}{*}{ G.L } & \multicolumn{5}{|c|}{ 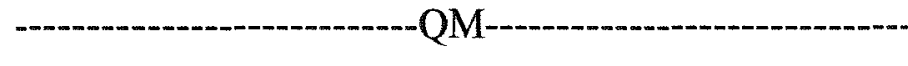 } \\
\hline & & PMSPA & NPA. & RAS. & M. NOD. & $\mathrm{N}^{\circ} \mathrm{NOD}$ \\
\hline Tratamento Químico solo (TQS) & 1 & $134,49 *$ & $0,0205 \mathrm{~ns}$ & $0,0387 \mathrm{~ns}$ & $1,5425^{*}$ & $65521,5^{*}$ \\
\hline Estirpe de rizóbio.(Est. R.) & 2 & $11,570^{*}$ & $0,0023 \mathrm{~ns}$ & $0,4086^{*}$ & $0,0109 \mathrm{~ns}$ & $414,9 \mathrm{~ns}$ \\
\hline Compactação (Comp.) & 3 & $10,390^{*}$ & $1,2921^{*}$ & $1,9383^{*}$ & $0,0251^{*}$ & $193,5 \mathrm{~ns}$ \\
\hline Efeito Linear & 1 & $28,598^{*}$ & $3,6690^{*}$ & $4,5858^{*}$ & $0,0073 \mathrm{~ns}$ & $\cdots$ \\
\hline Efeito Quadrático & 1 & $1,505 \mathrm{~ns}$ & $0,1472 \mathrm{~ns}$ & $0,7602^{*}$ & $0,0680^{*}$ & $-\cdots$ \\
\hline Independente da Regressão & 1 & $1,071 \mathrm{~ns}$ & $0,5920 \mathrm{~ns}$ & $0,4688^{*}$ & $0,0000 \mathrm{~ns}$ & ---- \\
\hline TQSxEst. R. & 2 & $0,493 \mathrm{~ns}$ & $0,1950^{*}$ & $0,8115^{*}$ & $0,0045 \mathrm{~ns}$ & $476,2 \mathrm{~ns}$ \\
\hline TQS x Comp. & 3 & $8,199^{*}$ & $0,0471 \mathrm{~ns}$ & $0,8298 *$ & $0,0299^{*}$ & $919,2^{*}$ \\
\hline Comp ${ }^{1} \mathrm{D} /$ Solo Com Brometo(SCB) & (3) & $46,243 *$ & & $11,473^{*}$ & $0,1331^{*}$ & $854,30^{*}$ \\
\hline Efeito Linear & 1 & $44,951^{*}$ & & $0,1963 \mathrm{~ns}$ & $0,0641^{*}$ & $832,5^{*}$ \\
\hline Efeito Quadrático & 1 & $0,753 \mathrm{~ns}$ & & $0,2452 *$ & $0,0665^{*}$ & $20,0 \mathrm{~ns}$ \\
\hline Independente da Regressão & 1 & $0,539 \mathrm{~ns}$ & & $11,032 \mathrm{~ns}$ & $0,0025 \mathrm{~ns}$ & $1,8 \mathrm{~ns}$ \\
\hline Comp D/Solo Sem Brometo(SSB) & (3) & $7,526^{*}$ & & $7,2678^{*}$ & $0,0321^{*}$ & $2483,7^{*}$ \\
\hline Efeito Linear & 1 & $0,737 \mathrm{~ns}$ & & $6,6847^{*}$ & $0,0175^{*}$ & $1755,10^{*}$ \\
\hline Efeito Quadrático & 1 & $6,773^{*}$ & & $0,5444 *$ & $0,0123 \mathrm{~ns}$ & $728,5 \mathrm{~ns}$ \\
\hline Independente da Regressão & 1 & $0,017 \mathrm{~ns}$ & & $0,0388 \mathrm{~ns}$ & $0,0023 \mathrm{~ns}$ & $0,2 \mathrm{~ns}$ \\
\hline Est. R. x Comp. & 6 & $2,853^{*}$ & $0,0748 \mathrm{~ns}$ & $1,2424^{*}$ & $0,0133^{*}$ & $820,4^{*}$ \\
\hline Comp D/ Nativa & (3) & $6,150^{*}$ & & $10,753 *$ & $0,0155^{*}$ & $15,21^{*}$ \\
\hline Efeito Linear & 1 & $5,268^{*}$ & & $9,5234^{*}$ & $0,0097 \mathrm{~ns}$ & $1316,7^{*}$ \\
\hline Efeito Quadrático & 1 & $0,856 \mathrm{~ns}$ & & $0,5949 *$ & $0,0050 \mathrm{~ns}$ & $30,0 \mathrm{~ns}$ \\
\hline Independente da Regressão & 1 & $0,026 \mathrm{~ns}$ & & $0,6397^{*}$ & $0,0008 \mathrm{~ns}$ & $174,3 \mathrm{~ns}$ \\
\hline
\end{tabular}




\begin{tabular}{|c|c|c|c|c|c|c|}
\hline Comp D/ SEMIA 5079 & (3) & $3,886^{*}$ & & $2,996^{*}$ & $0,1119^{*}$ & $3272,2^{*}$ \\
\hline Efeito Linear & 1 & $0,698 \mathrm{~ns}$ & & $0,2846^{*}$ & $0,0257^{*}$ & $18,2 \mathrm{~ns}$ \\
\hline Efeito Quadrático & 1 & $2,381^{*}$ & & $2,6038^{*}$ & $0,0727^{*}$ & $2888,0^{*}$ \\
\hline Independente da Regressão & 1 & $0,807 \mathrm{~ns}$ & & $0,1078 \mathrm{~ns}$ & $0,0135 \mathrm{~ns}$ & $366,0 \mathrm{~ns}$ \\
\hline Comp. D/ SEMIA 5080 & (3) & $38,253 *$ & & $0,5149^{*}$ & $0,0945 \mathrm{~ns}$ & $708,6 \mathrm{~ns}$ \\
\hline Efeito Linear & 1 & $37,598 *$ & & $0,0656 \mathrm{~ns}$ & $0,0740 \mathrm{~ns}$ & $257.5 \mathrm{~ns}$ \\
\hline Efeito Quadrático & 1 & $0,118 \mathrm{~ns}$ & & $0,4460^{*}$ & $0,0124 \mathrm{~ns}$ & $427,8 \mathrm{~ns}$ \\
\hline Independente da Regressão & 1 & $0,537 \mathrm{~ns}$ & & $0,0033 \mathrm{~ns}$ & $0,008 \operatorname{lns}$ & $23,3 \mathrm{~ns}$ \\
\hline TQS x Est. R. x Comp. & 6 & $1,363 \mathrm{~ns}$ & $0,0505 \mathrm{~ns}$ & $0,2449^{*}$ & $0,0045 \mathrm{~ns}$ & $360,5 \mathrm{~ns}$ \\
\hline Comp. D/Nativa /SCB & (3) & & & $2,7544^{*}$ & $-\cdots$ & --- \\
\hline Efeito Linear & 1 & & & $0,9038^{*}$ & $-\cdots$ & --- \\
\hline Efeito Quadrático & 1 & & & $0,6476^{*}$ & ----- & $-\cdots$ \\
\hline Independente Regressão & 1 & & & $1,2030^{*}$ & ----- & --- \\
\hline Comp. D/Nativa/SSB & (3) & & & $10,183^{*}$ & ---- & $-\cdots$ \\
\hline Efeito Linear & 1 & & & $10,101^{*}$ & -.-- & $-\cdots$ \\
\hline Efeito Quadrático & 1 & & & $0,0818 \mathrm{~ns}$ & -.-.- & --.- \\
\hline Independente da Regressão & 1 & & & $0,0013 \mathrm{~ns}$ & ---- & --- \\
\hline Comp. D/SEMIA5079/SCB & (3) & & & $1,6785^{*}$ & $-\cdots--$ & $-\cdots$ \\
\hline Efeito Linear & 1 & & & $0,009 \mathrm{~ns}$ & $-\cdots$ & --- \\
\hline Efeito Quadrático & 1 & & & $1,6679^{*}$ & $-\cdots$ & $-\cdots$ \\
\hline Independente da Regressão & 1 & & & $0,0016 \mathrm{~ns}$ & -.-- & $-\cdots$ \\
\hline Comp.D/SEMIA5079/SSB & (3) & & & $1,8826^{*}$ & ---- & --- \\
\hline Efeito Linear & 1 & & & $0,7212^{*}$ & ---- & $-\cdots$ \\
\hline Efeito Quadrático & 1 & & & $0,9811^{*}$ & ---- & $-\cdots$ \\
\hline Independente da Regressão & 1 & & & $0,1803 \mathrm{~ns}$ & ----- & --- \\
\hline Comp. D/SEMIA5080/SCB & (3) & & & $0,1856^{*}$ & $\cdots$ & --- \\
\hline Efeito Linear & 1 & & & $0,0078 \mathrm{~ns}$ & ---- & --- \\
\hline Efeito Quadrático & 1 & & & $0,1376 \mathrm{~ns}$ & $-\cdots-$. & --- \\
\hline Independente da Regressão & 1 & & & $0,0402 \mathrm{~ns}$ & ---- & $\cdots$ \\
\hline Comp.D/SEMIA5080/SSB & (3) & & & $0.5535 \mathrm{~ns}$ & -.-- & $-\ldots$ \\
\hline
\end{tabular}




\begin{tabular}{|c|c|c|c|c|c|c|}
\hline Efeito Linear & 1 & & & $0,2032^{*}$ & ---- & --- \\
\hline Efeito Quadrático & 1 & & & $0,3289^{*}$ & $-\cdots$ & $-\cdots$ \\
\hline Independente da Regressão & 1 & & & $0,0014 \mathrm{~ns}$ & ---- & --- \\
\hline Resíduo & 72 & 0,644 & 0,0451 & 0,0539 & 0,0044 & 203,9 \\
\hline Coeficiente de Variação \% & & 8,30 & 9,21 & 8,93 & 12,71 & 12,08 \\
\hline
\end{tabular}

* Significativo a $5 \%$ de probabilidade; ${ }^{\text {ns }}$ não significativo; ${ }^{1} \mathrm{D} /=$ dentro

Analisando o comportamento da produção de matéria seca da parte aérea em função dos níveis de compactação aplicados mas, dentro de cada estirpe de rizóbio estudado, observa-se pela Figura 2 um comportamento linearmente decrescente e altamente significativo dentro das estirpes nativa e SEMIA 5080. Com a inoculação da SEMIA 5079 a produção de matéria seca seguiu comportamento quadrático, com ponto de maior produção de matéria seca na densidade de solo de $1,34 \mathrm{~kg} \mathrm{dm}^{-3}$.

\subsection{Nitrogênio da parte aérea da soja}

Análise de variância dos dados de absorção e concentração de nitrogênio pela parte aérea da planta (Tabelas 4 e 5 ) evidenciam que não obstante ter sido observado ausência de significância para o tratamento químico de solo e estirpes de rizóbios, constata-se que os niveis de compactação aplicados bem como a interação tratamento químico de solo $x$ estirpes de rizóbios foram significativos a $5 \%$ de probabilidade.

Aplicação do teste de Tukey a $5 \%$ de probabilidade para comparar o efeito da desinfestação do solo para cada estirpe de rizóbio, revela que não há efeito desta tanto para estirpe nativa do solo como para a SEMIA 5080. Contudo, esta absorção e concentração do nitrogênio pela parte aérea foi significativamente menor no solo com brometo quando a estirpe de rizóbio inoculada foi a SEMIA 5079 (Tabela 5). Possivelmente a SEMIA 5080 seja mais competitiva em relação a SEMIA 5079 ou às nativas, eliminadas com a desinfestação do solo. 
Tabela 5. Concentração de nitrogênio na parte aérea em \%, da soja, submetidas ao tratamento químico de solo, estirpes de rizóbios e diferentes níveis de compactação do solo.

\begin{tabular}{|c|c|c|c|c|c|}
\hline \multirow{2}{*}{$\begin{array}{l}\text { Tratamento } \\
\text { Químico do solo }\end{array}$} & \multirow{2}{*}{$\begin{array}{l}\text { Densidade } \\
\mathrm{kg} \mathrm{dm}^{-3}\end{array}$} & \multicolumn{3}{|c|}{ Estirpes de Rizóbios } & \multirow[b]{2}{*}{ Médias } \\
\hline & & Nativa & SEMIA 5079 & SEMIA 5080 & \\
\hline & 1,15 & 2,45 & 2,38 & 2,59 & \\
\hline & 1,30 & 2,29 & 2,22 & 2,56 & \\
\hline \multirow[t]{2}{*}{ Com Brometo } & 1,45 & 2,36 & 2,04 & 2,23 & \\
\hline & 1,60 & 1,99 & 2,24 & 2,07 & \\
\hline \multirow[t]{3}{*}{ Médias } & & $2,28 \mathbf{a}$ & $\mathbf{2 , 2 3 b}$ & $2,37 \mathbf{a}$ & $2,29 \underline{A}$ \\
\hline & 1,15 & 2,64 & 2,59 & 2,65 & \\
\hline & 1,30 & 2,25 & 2,61 & 2,27 & \\
\hline \multirow[t]{2}{*}{ Sem Brometo } & 1,45 & 2,14 & 2,11 & 2,09 & \\
\hline & 1,60 & 2,33 & 2,33 & 1,91 & \\
\hline Médias & & 2,35a & $2,39 \mathrm{a}$ & $2,23 \mathrm{a}$ & $2,32 \underline{A}$ \\
\hline Média Geral & & $2,32 \mathrm{~A}$ & $2,31 \mathrm{~A}$ & $2,30 \mathrm{~A}$ & \\
\hline
\end{tabular}

- Médias seguidas por letras minúsculas distintas, na linha, diferem entre si a $5 \%$ de probabilidade pelo teste de Tukey.

- Médias seguidas por letras maiúsculas distintas, na linha, diferem entre si a $5 \%$ de probabilidade pelo teste de Tukey.

- Médias seguidas por letras maiúsculas sublinhadas e distintas, na coluna, diferem entre si a $5 \%$ de probabilidade pelo teste de Tukey.

Analisando a concentração de nitrogênio na parte aérea em função das estirpes estudadas e da desinfestação do solo, verifica-se através do teste de Tukey a 5\% de probabilidade (Tabela 5) que as três estirpes de rizóbios tiveram o mesmo comportamento no solo sem brometo. Já no solo com brometo, a SEMIA 5079 foi significativamente inferior às outras duas estudadas. 
O modelo de regressão estabelecido para avaliar o efeito dos níveis de compactação, foi possível visualizar que a quantidade de nitrogênio absorvido teve uma redução linear como mostra a equação $\mathrm{Y}=3,9-1,17 \mathrm{X}$ com $\mathrm{r}=0,97^{*}$, onde $\mathrm{Y}=$ nitrogênio absorvido e acumulado na parte aérea e $\mathrm{X}=$ níveis de compactação aplicado no anel central do vaso.

\subsection{Produção de raízes no anel superior da coluna}

Os dados obtidos com a coleta e quantificação das raízes presentes no anel superior da coluna, submetidos à análise de variância (Tabelas 4 e 6) mostram que houve efeito significativo tanto para os tratamentos como para algumas interações, evidenciando assim que a produção de raízes no anel superior da coluna em função de cada tratamento aplicado é dependente dos níveis em que cada um ocorre.

Observa-se pela Tabela 6 que no solo com brometo a produção de raízes no anel superior da coluna, dentro da compactação do solo, o tratamento sem inoculação de rizóbios foi maior do que quando efetuada a inoculação com as estirpes SEMIA 5079 e SEMIA 5080, as quais não diferiram entre si. Na ausência da desinfestação do solo, dentro da compactação, observa-se (Tabela 4 e 6) que ocorreu o inverso, ou seja, a inoculação das sementes com SEMIA 5079 e SEMIA 5080 possibilitou produção significativamente maior de raízes na camada superficial.

A maior produção de raízes no anel superior no solo com brometo em ausência da inoculação, possivelmente esteja relacionada com a eliminação de inimigos naturais das estirpes nativas, ou mesmo de predadores de raízes.

$\mathrm{O}$ teste de Tukey a $5 \%$ de probabilidade, aplicado às médias das três estirpes de rizóbios dentro dos tratamentos solo com brometo e solo sem brometo mostra que a brometização possibilitou maior produção de raízes quando a camada subsuperficial não era compactada, não ocorrendo, no entanto, diferenças para o tratamento químico do solo nas densidades de 1,30 e $1,45 \mathrm{~kg} \mathrm{dm}^{-3}$. 
Tabela 6. Produção de raízes de soja, no anel superior da coluna, submetidas ao tratamento químico de solo, inoculação de sementes com estirpes de rizóbios e diferentes níveis de compactação do solo do anel central.

\begin{tabular}{|c|c|c|c|c|c|}
\hline \multirow{2}{*}{$\begin{array}{l}\text { Densidade } \\
\left(\mathrm{Kg} \mathrm{dm}^{-3}\right)\end{array}$} & \multirow{2}{*}{$\begin{array}{c}\text { Tratamento } \\
\text { Químico }\end{array}$} & \multicolumn{3}{|c|}{ Estirpes de Rizóbios } & \multirow[b]{2}{*}{ Médias } \\
\hline & & Nativa & SEMIA5079 & SEMIA5080 & \\
\hline & Com Brometo & $2,941 \mathrm{a}-\mathrm{A}$ & $2,192 \mathrm{bA}$ & $2,412 \mathrm{bA}$ & $2,515 A$ \\
\hline 1,15 & Sem Brometo & $1,538 \mathrm{bB}$ & $2,134 \mathrm{aA}$ & $2,292 \mathrm{aA}$ & $1,988 \mathrm{~B}$ \\
\hline \multirow[t]{2}{*}{ Médias } & & $2,239 \underline{a}$ & $2,163 \underline{a}$ & $2,352 \underline{a}$ & \\
\hline & Com Brometo & $2,261 \mathrm{bA}$ & $2,799 \mathrm{aA}$ & $2,488 \mathrm{abA}$ & $2,516 \mathrm{~A}$ \\
\hline 1,30 & Sem Brometo & $2,089 \mathrm{bB}$ & $2,629 a A$ & $2,733 \mathrm{aA}$ & $2,484 A$ \\
\hline \multirow[t]{2}{*}{ Médias } & & $2,175 \underline{b}$ & $2,714 \underline{\mathbf{a}}$ & $2,610 \underline{\mathrm{a}}$ & \\
\hline & Com Brometo & $3,209 \mathrm{aA}$ & $2,804 \mathrm{bA}$ & $2,603 \mathrm{bA}$ & $\mathbf{2 , 8 7 2 A}$ \\
\hline 1,45 & Sem Brometo & $2,824 \mathrm{aB}$ & $3,104 a A$ & $2,754 \mathrm{aA}$ & $2,894 \mathrm{~A}$ \\
\hline \multirow[t]{2}{*}{ Médias } & & $3,016 \underline{a}$ & $2,954 \underline{a b}$ & $2,678 \underline{b}$ & \\
\hline & Com Brometo & $3,333 \mathrm{aB}$ & $2,120 \mathrm{bB}$ & $2,308 \mathrm{bA}$ & $2,587 \mathrm{~B}$ \\
\hline 1,60 & Sem Brometo & $3,661 \mathrm{aA}$ & $2,609 \mathrm{bA}$ & $2,621 \mathrm{bA}$ & $2,964 \mathrm{~A}$ \\
\hline \multicolumn{2}{|l|}{ Médias } & $3,498 \underline{a}$ & $2,364 \underline{b}$ & $2,464 \underline{b}$ & \\
\hline \multicolumn{2}{|c|}{ Média solo Com Brometo D/compactação } & $2,936 A$ & $2,479 A$ & $2,453 A$ & \\
\hline \multicolumn{2}{|c|}{ Média solo Sem BrometoD/compactação } & $2,528 B$ & $2,619 A$ & $2,599 A$ & \\
\hline \multicolumn{6}{|c|}{$\begin{array}{l}\text { - Médias seguidas por letras minúsculas distintas, na linha, diferem entre si a } 5 \% \text { de } \\
\text { probabilidade pelo teste de Tukey. }\end{array}$} \\
\hline \multicolumn{6}{|c|}{$\begin{array}{l}\text { - Médias de médias seguidas por letras minúsculas sublinhadas e distintas, na linha, diferem } \\
\text { entre si a } 5 \% \text { de probabilidade pelo teste de Tukey. }\end{array}$} \\
\hline \multicolumn{6}{|c|}{$\begin{array}{l}\text { - Médias seguidas por letras maiúsculas cortadas e distintas, na coluna, diferem entre si a } 5 \\
\% \text { de probabilidade pelo teste de Tukey. }\end{array}$} \\
\hline \multicolumn{6}{|c|}{$\%$ de probabilidade pelo teste de Tukey. } \\
\hline \multicolumn{6}{|c|}{ - Médias de médias seguidas por letras maiúsculas, na coluna, distintas diferem entre si a 5} \\
\hline
\end{tabular}


Observa-se na Tabela 6 que a produção de raizes no anel superior, na ausência de inoculação (estirpe nativa) de maneira geral, apresentou o mesmo comportamento dentro de cada nível de compactação a que foi submetido o solo do anel central, ou seja, sendo que esta produção era significativamente superior quando o solo era submetido ao tratamento da desinfestação, sendo exceção a densidade de $1,60 \mathrm{~kg} \mathrm{dm}$ ${ }^{3}$, onde a não desinfestação do solo proporcionou maior produção de raízes. Com a inoculação das estirpes SEMIA 5079 e SEMIA 5080, observa-se (Tabela 6) que a produção de raízes não foi afetada pela desinfestação dentro das densidades de $1,15,1,30$ e $1,45 \mathrm{~kg} \mathrm{dm}^{-3}$. Na densidade de $1,60 \mathrm{~kg} \mathrm{dm}^{-3}$ a inoculação com a SEMIA 5079 proporcionou produção de raizes maior quando o solo era sem brometo.

Considerando o comportamento médio das estirpes dentro de cada densidade observa-se (Tabela 6) que a produção de raízes não foi influenciada pelas estirpes estudadas quando o solo não foi submetido a compactação (densidade de $1,15 \mathrm{~kg} \mathrm{dm}^{-3}$ ). Com a compactação, observa-se que a produção das raizes no tratamento sem inoculação foi significativamente superior quando as estirpes SEMIA 5079 e SEMIA 5080 foram inoculadas, dentro das densidades 1,45 e $1,60 \mathrm{~kg} \mathrm{dm}^{3}$

Analisando a produção de raízes do anel superior com o solo com brometo, observa-se que onde não foi feita a inoculação, a produção foi significativamente superior aos tratamentos inoculados nas densidades de 1,$15 ; 1,45$ e $1,60 \mathrm{~kg} \mathrm{dm}^{-3}$, enquanto que, para o solo sem brometo a inoculação com as estirpes SEMIA 5079 e SEMIA 5080 não diferiram entre si e foram significativamente superiores ao tratamento sem inoculação dentro das densidades de 1,15 e $1,30 \mathrm{~kg} \mathrm{dm}^{-3}$. Na densidade de $1,45 \mathrm{~kg} \mathrm{dm}^{-3}$ não foi observado efeito significativo entre as estirpes estudadas. $\mathrm{Na}$ densidade de $1,60 \mathrm{~kg} \mathrm{dm}^{-3}$ observa-se que as estirpes SEMIA 5079 e SEMIA 5080 não diferiram entre si e foram significativas inferiores nativa (Tabela 6).

Os dados de produção de raízes no anel superior em função dos níveis de compactação para cada tipo de tratamento de solo e estirpes de rizóbios foram submetidos à regressão (Figuras 3 e 4). A existência de significância para interação dupla e tripla (Tabela 4) evidência que a produção de raízes em função da compactação é dependente tanto do tratamento da desinfestação como da estirpe rizóbios. 


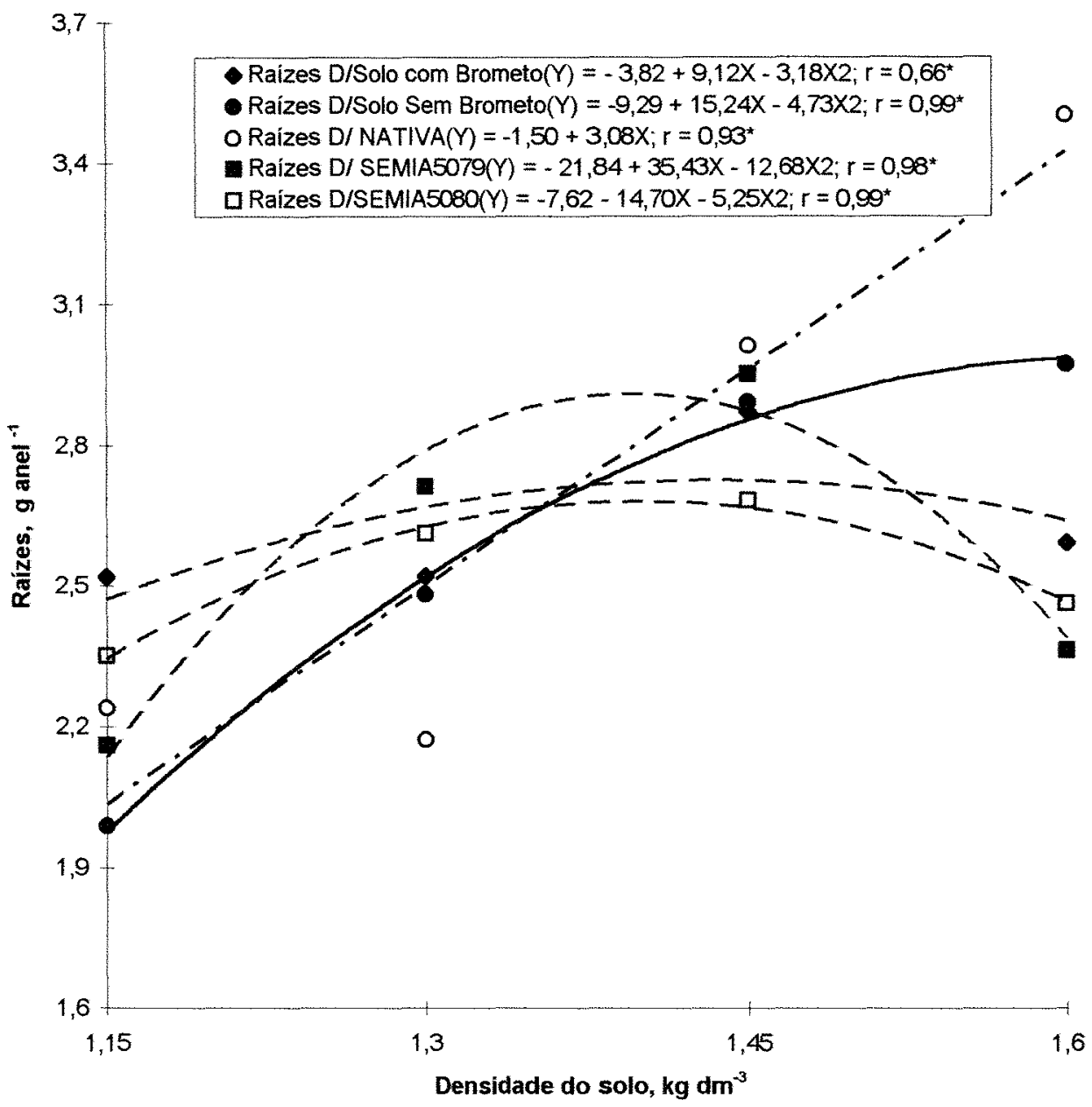

Figura 3-Equações de regressão ajustada para produção de massa seca de raízes da soja, no anel superior da coluna, em g, dentro de tratamento químico do solo e de inoculação de estirpes de rizóbios, em função da densidade do solo do anel central da coluna $(\mathrm{X})$, em $\mathrm{kg} \mathrm{dm}^{-3}$ 


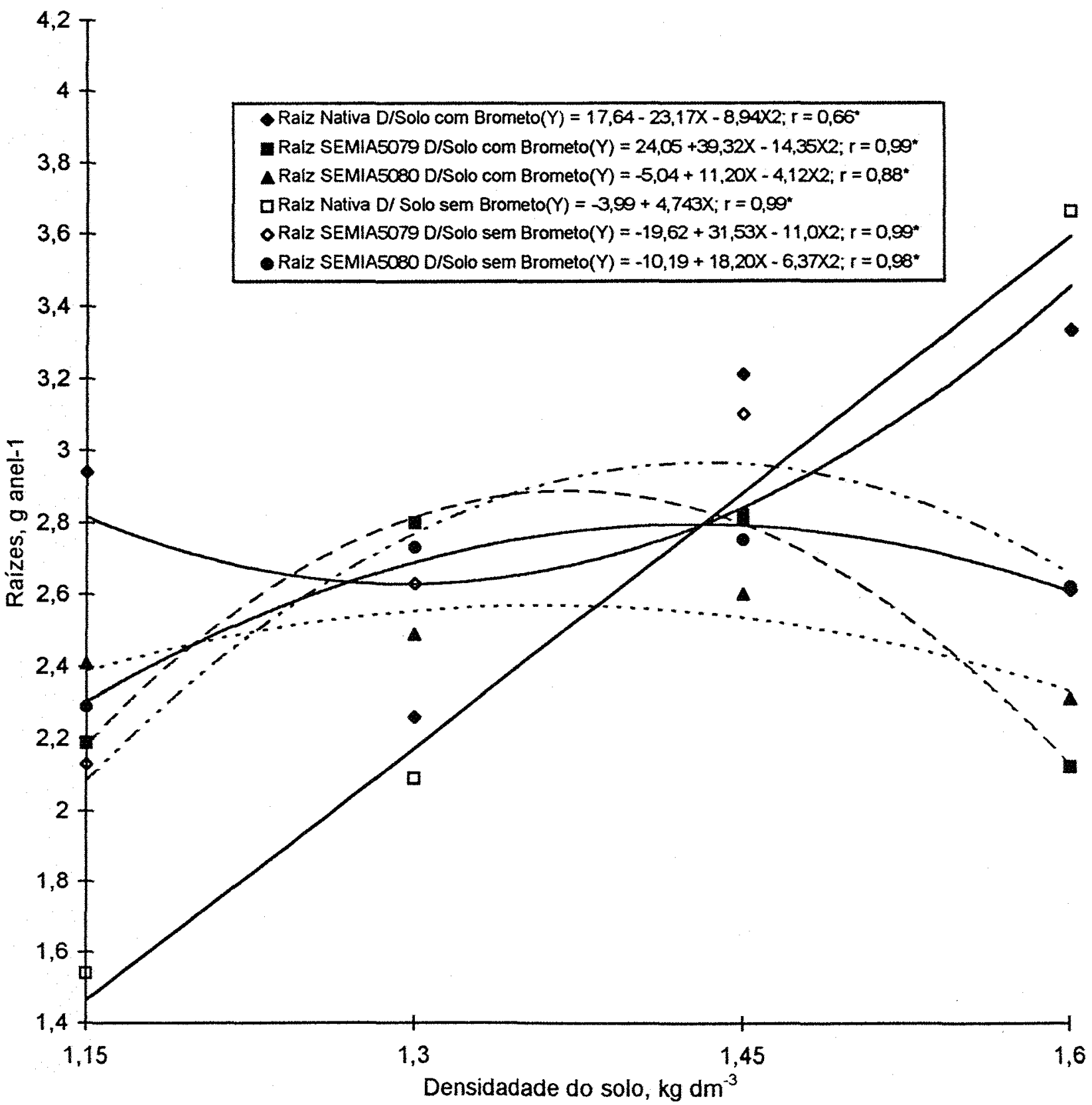

Figura 4- Equações de regressão ajustadas para produção de massa seca de raízes de soja, no anel superior da coluna, em g, para cada estirpe de rizóbio inoculado, dentro de tratamento quimico do solo, em função da densidade do solo do anel central da coluna, $(\mathrm{X}), \mathrm{em} \mathrm{kg} \mathrm{dm}{ }^{-3}$ 
Observa-se pela Figura 3 que o ajuste da equação quadrática tendo como variável dependente a produção de raízes no anel superior(Y) e independente a densidade do solo(X) possui ponto de máximo em $1,43 \mathrm{Kg} \mathrm{dm}^{-3}$ para o solo com brometo e $1,61 \mathrm{~kg}$ $\mathrm{dm}^{-3}$ para o solo sem brometo.

O estabelecimento de equações quadráticas no solo com brometo (Figura 4) com ponto de mínimo para densidade de $1,30 \mathrm{~kg} \mathrm{dm}^{-3}$ para a estirpe nativa, e de mäximo e $1,37 \mathrm{~kg} \mathrm{dm}^{-3}$ para SEMIA 5079 e de $1,36 \mathrm{~kg} \mathrm{dm}^{-3}$ para SEMIA 5080 mostra que a compactação pode exercer um efeito diferenciado entre estirpe de rizóbio. Para o solo sem brometo observa-se que, quando não houve inoculação, a produção de raízes no anel superior foi linearmente crescente com a compactação, enquanto que com a inoculação das estirpes SEMIA 5079 e SEMIA 5080 a produção de raízes seguiu comportamento quadrático com pontos de máximos nas densidades de $1,43 \mathrm{~kg} \mathrm{dm}^{-3}$ para ambas estirpes, conforme pode ser observado pela derivada primeira das equações (Figura 4).

\subsection{Massa dos nódulos do anel superior da coluna}

A compactação bem como a inoculação de estirpes de rizóbios e o tratamento químico do solo, afetaram significativamente a massa dos nódulos coletados nas raizes do anel superior da coluna (Tabelas 4 e 7 ).

A existência de interação significativa entre tratamento químico do solo $\mathrm{x}$ compactação e de estirpes de rizóbios $\mathrm{x}$ compactação do solo indica que os tratamentos que compõem estas interações tiveram comportamentos diferenciados dentro de cada nível do seu correspondente (Tabela 4 ). Assim, o estudo foi desdobrado, estudando o efeito de tratamento químico do solo e da inoculação de rizóbios dentro dos níveis de compactação e vice-versa.

Considerando os efeitos dentro de cada densidade do solo observa-se (Tabela 7) que o tratamento da desinfestação do solo possibilitou aumento significativo da massa dos nódulos em todos os níveis de compactação. Possivelmente, a desinfestação tenha propiciado melhores condições para a ocorrência da nodulação. 
Tabela 7. Massa, $g$ anel ${ }^{-1}$, e número de nódulos das raizes de soja, coletadas no anel superior da coluna, submetidas ao tratamento químico de solo, com e sem inoculação de sementes, em diferentes níveis de compactação do solo do anel central.

\begin{tabular}{|c|c|c|c|c|c|}
\hline \multirow{2}{*}{$\begin{array}{l}\text { Densidade } \\
\left(\mathrm{Kg} \mathrm{dm}^{-3}\right)\end{array}$} & \multirow{2}{*}{$\begin{array}{c}\text { Tratamento } \\
\text { Químico }\end{array}$} & \multicolumn{3}{|c|}{ Estirpes de Rizóbios } & \multirow[b]{2}{*}{ Médias } \\
\hline & & Vativa & SEMIA5079 & SEMIA5080 & \\
\hline & & \multicolumn{4}{|c|}{ - - } \\
\hline & Com Brometo & 0,671 & 0,667 & 0,654 & $0,664 A$ \\
\hline 1,15 & Sem Brometo & 0,347 & 0,331 & 0,375 & $0,351 \mathrm{~B}$ \\
\hline \multirow[t]{2}{*}{ Médias } & & $0,509 a$ & $0,499 \mathrm{a}$ & $0,515 a$ & \\
\hline & Com Brometo & 0,657 & 0,768 & 0,654 & $0,693 \mathrm{~A}$ \\
\hline 1,30 & Sem Brometo & 0,424 & 0,443 & 0,370 & 0,412 B \\
\hline \multirow[t]{2}{*}{ Médias } & & 0,541 àb & $0,605 a$ & $0,512 b$ & \\
\hline & Com Brometo & 0,703 & 0,664 & 0,673 & $0,679 A$ \\
\hline 1,45 & Sem Brometo & 0,437 & 0,387 & 0,409 & 0,411 B \\
\hline \multirow[t]{2}{*}{ Médias } & & $0,569 a$ & $\mathbf{0 , 5 2 5 a}$ & 0,541 a & \\
\hline & Com Brometo & 0,667 & 0,513 & 0,499 & $0,559 \mathrm{~A}$ \\
\hline 1,60 & Sem Brometo & 0,435 & 0,370 & 0,420 & $0,408 \mathrm{~B}$ \\
\hline \multirow[t]{3}{*}{ Médias } & & $0,551 \mathrm{a}$ & $0,441 b$ & $0,459 b$ & \\
\hline & & \multicolumn{4}{|c|}{ Números de Nódulos - } \\
\hline & Com Brometo & 136,7 & 143,0 & 167,8 & $149,2 \mathrm{~A}$ \\
\hline 1,15 & Sem Brometo & 74,3 & 77,8 & 88,3 & 80,1 B \\
\hline \multirow[t]{2}{*}{ Médias } & & $105,5 b$ & $110,4 b$ & $128,0 a$ & \\
\hline & Com Brometo & 136,0 & 164,5 & 140,8 & $147,1 \mathrm{~A}$ \\
\hline 1,30 & Sem Brometo & 82,0 & 105,0 & 92,5 & $93,2 \mathrm{~B}$ \\
\hline \multirow[t]{2}{*}{ Médias } & & $109,0 \mathrm{~b}$ & $134,8 \mathbf{a}$ & $116,6 \mathrm{~b}$ & \\
\hline & Com Brometo & 152,5 & 147,0 & 129,0 & $142,8 \mathrm{~A}$ \\
\hline 1,45 & Sem Brometo & 89,5 & 103,0 & 103,8 & $98,8 \mathrm{~B}$ \\
\hline \multirow[t]{2}{*}{ Médias } & & $121,0 \mathbf{a}$ & $125,0 \mathrm{a}$ & $116,4 a$ & \\
\hline & Com Brometo & 150,0 & 133,0 & 131,5 & $138,2 \mathrm{~A}$ \\
\hline 1,60 & Sem Brometo & 91,3 & 89,8 & 107,8 & $96,3 \mathrm{~B}$ \\
\hline Médias & & $120,6 a$ & $111,4 a$ & $119,6 a$ & \\
\hline
\end{tabular}

- Médias seguidas por letras minúsculas distintas na linha diferem entre si a $5 \%$ de probabilidade pelo teste de Tukey.

- Médias seguidas por letras maiúsculas distintas na coluna diferem entre si a $5 \%$ de probabilidade pelo teste de Tukey. 
Quanto às estirpes de rizóbios inoculadas, observa-se que a massa dos nódulos das plantas dos tratamentos inoculados não diferiu significativamente do observado nos tratamentos sem inoculação quando a densidade do solo do anel central da coluna variava de 1,15 e $1,45 \mathrm{~kg} \mathrm{dm}^{-3}$. Dentro da densidade de $1,60 \mathrm{~kg} \mathrm{dm}^{-3}$ os nódulos dos tratamentos não inoculados foram significativamente superiores aos observados nos tratamentos inoculados que não diferiram entre si. Como a compactação subsuperficial reduz tanto a macroporosidade como a velocidade de infiltração da água no solo (Borges, 1995), é possível que as irrigações tenham possibilitado a formação de um ambiente redutor na superficie mais prejudicial as estirpes inoculadas do que as estirpes nativas do solo.

Cattelan \& Vidor (1990) afirmam que a sobrevivência de microrganismos do solo, inclusive de rizóbios são dependentes de caraterísticas fisicas como aeração, teor de umidade e disponibilidade de nutrientes, fatores que podem ser influenciados pelo nível de compactação do solo.

As equações de regressão ajustadas para avaliar o efeito dos níveis de compactação $(\mathrm{X})$ sobre a massa seca dos nódulos (Y) (Figura 5) mostram que estes apresentaram comportamento quadrático com os valores de densidade do solo, sendo que a maior massa seca foi observado quando a densidade era de $1,30 \mathrm{~kg} \mathrm{dm}^{-3}$ quando o solo foi submetido a uma prévia desinfestação. Quando o solo não foi submetido a desinfestação observa-se (Figura 5) que a massa dos nódulos cresceu linearmente com os níveis de compactação aplicados no anel central do vaso. Pesquisas visando avaliar o efeito da compactação na nodulação e na eficiência dessa nodulação são praticamente inexistentes em nossas condições. Contudo, algumas inferências podem ser obtidas.

Considerando que a compactação irá provocar uma série de alterações nos atributos físicos e químicos do solo, as quais tem influência direta $\mathrm{e}$ indireta no desenvolvimento dos rizóbios, o comportamento quadrático observado para a nodulação (Figura 5) mostra que a compactação efetuada para obtenção de densidades acima de 1,33 $\mathrm{kg} \mathrm{dm}^{-3}$ nas estirpes SEMIA 5079 e SEMIA 5080, pode ter afetado o fornecimento do oxigênio ou mesmo ter propiciado condições para formação de elementos tóxicos que poderiam inibir ou prejudicar a nodulação. 


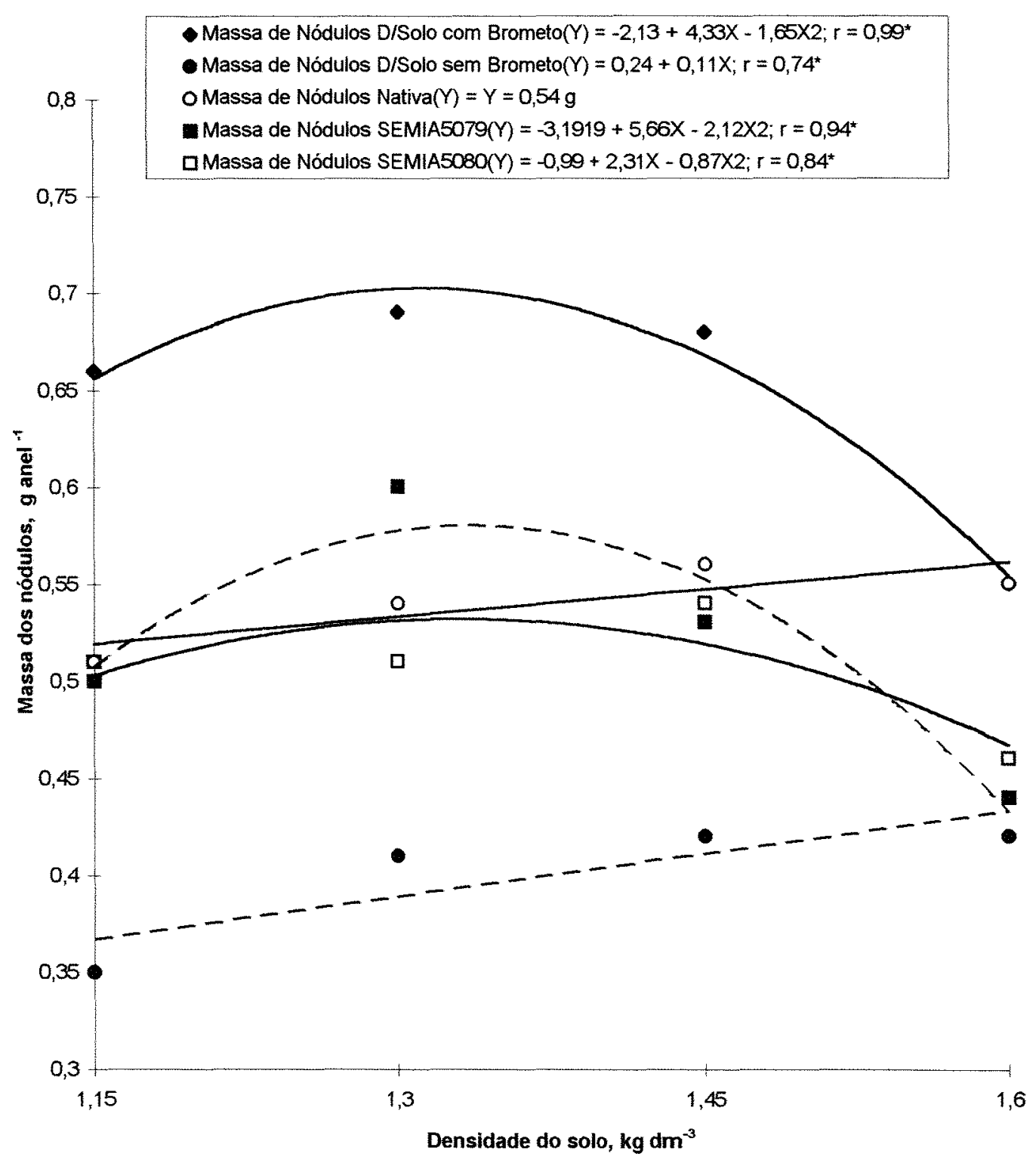

Figura 5- Equações de regressão ajustadas para produção de massa seca de nódulos de rizóbios, no anel superior da coluna, em g, dentro de tratamento químico do solo e de inoculação de estirpes de rizóbios, em função da densidade do solo do anel central (X), em $\mathrm{kg} \mathrm{dm}^{-3}$ 
Observa-se que, dentro do tratamento sem inoculação não houve efeito dos níveis de compactação, ou seja, para qualquer valor de densidade estudada a massa dos nódulos foi em média $\mathrm{Y}=\mathrm{Y}=0,54 \mathrm{~g}$. Com a inoculação da SEMIA 5079 o efeito dos níveis de compactação foi quadrático, sendo significativo a $5 \%$ de probabilidade pelo teste F. A derivada primeira desta equação possibilitou estimar que a maior massa seca dos nódulos é obtido com densidade de $1,33 \mathrm{~kg} \mathrm{dm}^{-3}$. Para a estirpe SEMIA 5080 o ajuste foi também quadrático, contudo, os coeficientes de regressão foram significativos a $10 \%$ de probabilidade pelo teste F. Maior massa dos nódulos, estimado pela derivada primeira da equação, ocorreu quando a densidade do solo do anel central era $1,33 \mathrm{~kg} \mathrm{dm}^{-3}$

\subsection{Número de nódulos do anel superior da coluna}

Análise de variância aplicada aos dados da Tabela 7 mostra que os tratamentos principais como a inoculação com estirpes de rizóbios e de níveis de compactação não influenciaram significativamente o número de nódulos, quantificado no sistema radicular do anel superior do vaso. Efeito estatisticamente significativo para as interações tratamento químico do solo $\mathrm{x}$ níveis de compactação $\mathrm{e}$, entre estirpes de rizóbios $\mathrm{x}$ níveis de compactação caracterizam a dependência entre os tratamentos efetuados com o nível em que ocorre cada um.

Teste de Tukey a $5 \%$ de probabilidade evidencia que a desinfestação possibilitou um número significativamente maior de nódulos no anel superior da coluna em relação ao solo não desinfestado (Tabela 7) tomando-se como média os quatro níveis de compactação efetuados no anel central.

Estudo da influencia de cada estirpe dentro dos níveis de compactação (Tabela 7), revela que dentro da densidade $1,15 \mathrm{~kg} \mathrm{dm}^{-3}$ a SEMIA 5080 possibilitou um número significativamente maior de nódulos em relação a SEMIA 5079 e a nativa, as quais não diferiram entre si pelo teste de Tukey a $5 \%$ de probalidade. Dentro da densidade $1,30 \mathrm{~kg} \mathrm{dm}^{-3}$ observa-se que foi a estirpe SEMIA 5079 quem possibilitou a obtenção do maior números de nódulo. Para as densidades $1,45 \mathrm{e} 1,60 \mathrm{~kg} \mathrm{dm}^{-3}$ as estirpes não apresentaram comportamentos diferenciados entre si, com relação a produção de nódulos. 


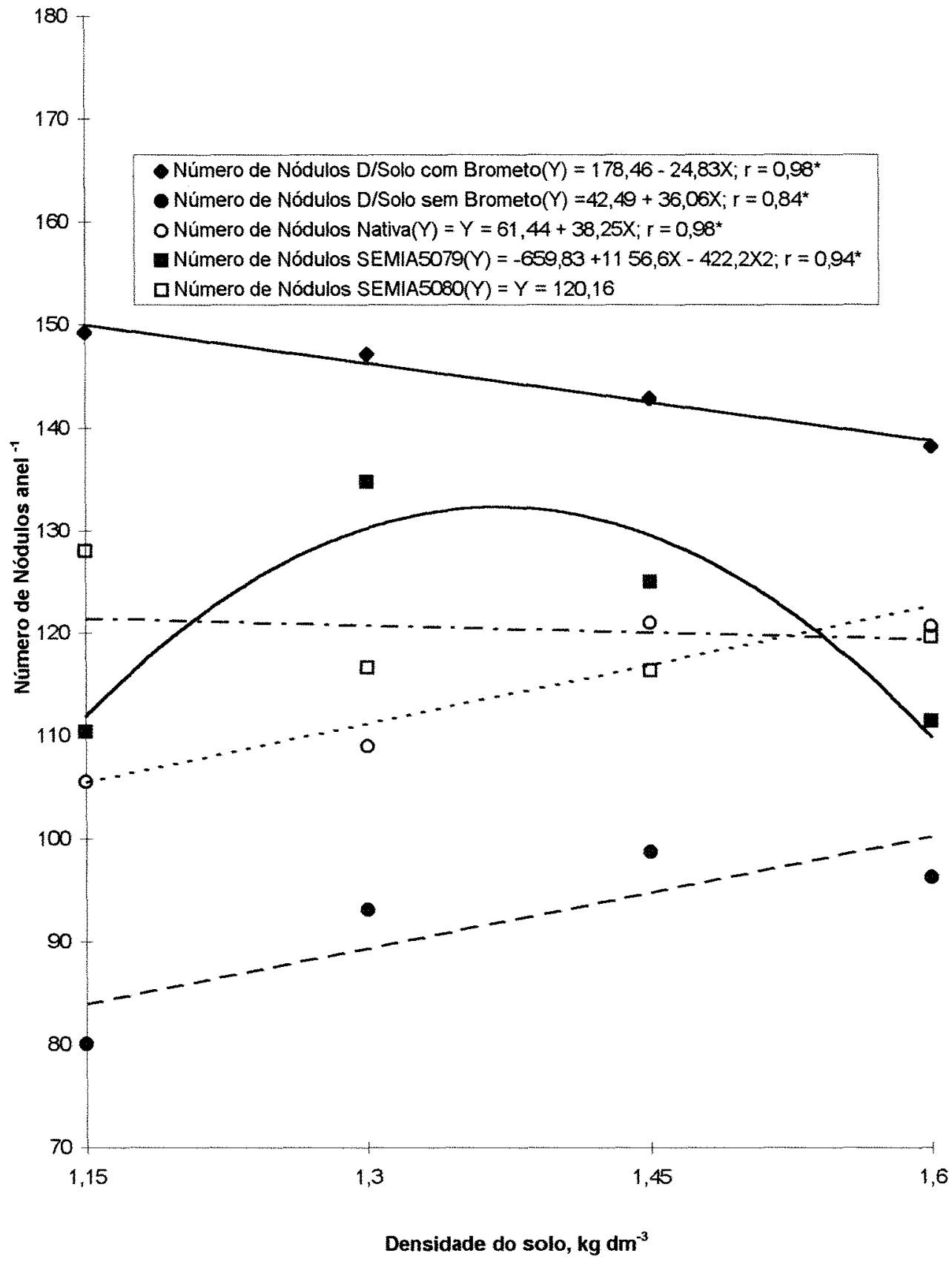

Figura 6- Equações de regressão ajustadas para número de nódulos de rizóbios, no anel superior da coluna, dentro de tratamento químico do solo e de inoculação de estirpes de rizóbios, em função da densidade do solo do anel central da coluna (X), em $\mathrm{kg} \mathrm{dm}^{-3}$ 
A restrição física ao desenvolvimento radicular pela presença da camada compactada no anel central além de ter proporcionado um ambiente redutor devido à baixa taxa de infiltração de água proveniente das irrigações, condicionou a planta a um menor crescimento radicular em profundidade o que pode ter afetado a nodulação.

As regressões ajustadas para mostrar o efeito da compactação $(\mathrm{X})$ no número de nódulos $(\mathrm{Y})$ encontram-se na Figura 6 . Através destas é possível perceber que no solo desinfestado o número de nódulos decresceu linearmente com o aumento da densidade do solo do anel central da coluna, enquanto que, no solo sem brometo o número cresceu linearmente. Este comportamento diferenciado com relação ao tratamento químico do solo pode estar relacionado com a presença de outras estirpes nativas presentes no solo sem brometo. Contudo, o aumento do número de nódulos no solo sem brometo, com os níveis de compactação, não levou a um aumento da massa destes nódulos (Tabela 7).

Regressões ajustadas para descrever o efeito dos niveis de compactação (X) no número de nódulos presentes no anel superior, dentro de cada estirpe, mostram (Figura 6) que o número de nódulos cresceu linearmente com a compactação dentro da estirpe nativa do solo, foi quadrática dentro da estirpe SEMIA 5079 sendo $1,37 \mathrm{~kg} \mathrm{dm}^{-3} \mathrm{a}$ densidade estimada para maior produção de nódulos, não havendo efeito da compactação dentro da SEMIA 5080 .

\section{CONCLUSÕES}

A análise e a interpretação dos dados possibilitaram concluir que:

a) A produção de matéria seca da parte aérea da soja, a massa e o número de nódulos foram maiores no solo desinfestado com brometo em todos os níveis de compactação.

b) A estirpe SEMIA 5080 proporcionou maior produção de matéria seca da parte aérea em todos os níveis de compactação, independente do tratamento químico do solo.

c) A concentração de nitrogênio na planta decresceu linearmente com compactação. 
d) A massa seca dos nódulos cresceu com a compactação até a densidade de $1,33 \mathrm{~kg} \mathrm{dm}^{-3}$, reduzindo drasticamente para valores maiores do que este, tanto na estirpe SEMIA 5080 como na SEMIA 5079.

e) Os níveis de compactação aplicados não influenciaram o número de nódulos da SEMIA 5080 e promoveram aumentos da SEMIA 5079 até a densidade do solo de $1,37 \mathrm{~kg} \mathrm{dm}^{-3}$. 


\section{REFERÊNCIAS BIBLIOGRÁFICAS}

ALVARENGA, C.R. Potencialidade de adubos verdes para conservação e recuperação de solos. Viçosa, 1993. 112p. Tese (Doutorado) - Universidade Federal de Viçosa.

ANJOS, J.T.; UBERTI, V.J.; LEITE, G.B.; KRIEGER, M. Propriedades físicas em solos sob diferentes sistemas de uso e manejo. R. bras. Ci. Solo, Campinas, v.18, p.27-36, 1994.

ASANUMA, S.; AYANABA, A. Variation in acid-Al tolerance of Bradyrhizobium japonicum strains from African soils. Soil Sci. Plant Nutr., v.36, p.309-317, 1990.

BACCHI, O.O.S. Efeito da compactação sobre o sistema solo-panta em cultura de canade-açúcar (Saccharum spp). Piracicaba, 1976. 65p. Dissertação (M.S.)- Escola Superior de Agricultura "Luiz de Queiroz", Universidade de São Paulo.

BERTOL, I. Erosão hídrica em cambissolo húmico distrófico sob diferentes preparos do solo e rotação de culturas. R. bras. Ci. Solo, Campinas, v.18, p.267-271, 1994.

BOHLOOL, P.B.; SCHMIDT, E.L. Persistence and competition aspects of $R$ japonicum observed in soil by imunufluorescence microscopy. Soil Sci. Soc. Amer. Proc., v.57, p.561-564, 1973.

BORGES, E.N. Efeito de doses de gesso+matéria seca de crotalária e de níveis de compactação em atributos físicos de um latossolo vermelho-escuro. Piracicaba, 1995, 136p. Tese(Doutorado) - Escola Superior de Agricultura "Luiz de Queiroz", Universidade deSão Paulo. 
BORGES, E.N.; NOVAIS, R.F.; BARROS, N.F.; COSTA, L.M; NEVES, J.C.L. Respostas de mudas de eucalipto a camadas compactadas de solo. Revista Árvore, v.10(2), p.181-195, 1987.

BORGES, E.N.; NOVAIS,R.F.; BARROS, N.F.; REGAZZI, A.J.; FERNANDES, B. Respostas de variedades de soja à compactação de camada de solo. Revista Ceres, v.35(202), p.553-68, 1988.

BORGES, E.N.; LOMBARDI NETO, F; CORREAA, G.F.; COSTA, L.M. Misturas de gesso e matéria orgânica alterando atributos físicos de um latossolo com compactação simulada. R. bras. Ci. Solo, v.21, p.125-130, 1997.

CAMARGO, A.O. Compactação do solo e desenvolvimento de plantas. Campinas: Fundação Cargill, 1983. 44p.

CAMARGO, O.A. de.; ALLEONI, L.R.F. Compactação do solo e o desenvolvimento das plantas. Piracicaba: USP/ESALQ, 1997. 132p.

CARVALHO Jr., I. A. Estimativas de parâmetros sedimentológicos para estudo de camadas compactadas e/ou adensadas em Latossolo de textura média, sob diferentes aspectos. Viçosa, 1995 , 83p. Dissertação (M.S.) - Universidade Federal de Viçosa

CASSEL, D.K. Mechanical properties and tillage requirements of sandy soils. Adv. Agron., New York, v.1, p. 39-50, 1991.

CATTELAN, A.J.; HUNGRIA, M. Nitrogen nutrition and inoculation. In: FAO, ed. Tropical Soybean - Improvement and prodution. Rome: FAO, 1994. P.201-215.

CATTELAN, A.J. \& VIDOR, C. Flutuações na biomassa, ativdidade e população microbiana do solo em função de variações ambentais. R. bras. Ci. Solo, v.14, p. 133-142, 1990.

CINTRA, F.L.D.; MIELNICZUCK, J. Potencial de algumas espécies vegetais para recuperação de solos com propriedades físicas degradadas. R. bras. Ci. Solo, v.7, p.323-327, 1983. 
CINTRA, F.L.D.; MIELNICZUK, J.; SCOPEL, F. Caracterização do impedimento mecânico em um latossolo roxo do Rio Grande do Sul. R. bras. Ci. Solo, Campinas, v. 7, p. 323-327, 1983.

COLLOZZI-FILHO, A; BALOTA, E.L. Micorrizas arbusculares. In: HUNGRIA, M; ARAUJO, R.S. Manual de métodos empregados em estudos de microbiologia agrícola. Brasília: EMBRAPA, 1994, p. 383-418.

COSTA, J.B. da. Caracterização e constituição do solo. Lisboa: Fundação Calouste Gulbenkian, 1979. 527p.

COSTA, M.P. Efeito da matéria argânica em alguns atributos do solo. Piracicaba, 1983. 137p. Dissertação (M.S.) - Escola Superior de Agricultura Luiz de Queiroz, Universiade de São Paulo.

EAVES, B.W; RATLIFE, L.F; TAYLOR, J.M. Use of a dead-load technique to determine axial root growth pressure. Agron. j., v.61, p.640-643, 1969.

EMPRESA BASILEIRA DE PESQUISA AGROPECUÁRIA. Relatório Técnico anual do centro de pesquisa agropecuária dos cerrados 1976 - 1978. Brasília: EMBRAPA - CPAC, 1979a. 183p.

EMPRESA BASILEIRA DE PESQUISA AGROPECUÁRIA. Serviço Nacional de Levantamento e Conservação de Solos. Manual de métodos de análise de solo. Rio de Janeiro: 1979b. n.p.

EMPRESA BRASILEIRA DE PESQUISA AGROPECUÁRIA. Centro de Pesquisa Agropecuária dos Cerrados. Relatórios Técnicos Anual 1980-1981, Brasilia: 1982. EMPRESA BRASILEIRA DE PESQUISA AGROPECUÁRIA . SERVIÇO NACIONAL DE LEVANTAMENTO E CONSERVAÇÃO DE SOLOS. Levantamento de reconhecimento de média intensidade e aptidão agrícola dos solos do Triângulo Mineiro. Rio de Janeiro: 1982. 
FRANCO, A.A.; DOBEREINER, J. Toxidez de manganês de solo ácido na simbiose, soja-Rhizobium. Pesq. Agropec. Bras., v.6, p.57-66, 1971.

FRANCO, A.A; VINCENT, J.M. Competition amongst rhizobia strains for the colonization and nodulation of two tropical legumes. Plant Soil., v.45: p.2742, 1976.

FREITAS, P.L. DE. Aspectos físicos e biológicos do solo. In: LANDERS, J.N. Fascículo de experiências de plantio direto no cerrado.Goiânia: Associação de Plantio Direto no Cerrado, 1994, p.199-213.

GARCIA-BLASQUEZ, M.C.; VIDOR, C.; MENDES, N. G. Aumento da fixação de nitrogênio em soja por inoculação, irrigação e cobertura do solo. R. bras. Ci. Solo, v. 15, p.179-85, 1991.

GRABLE, A.R. Soil aeration and plant growth. Advances in Agronomy, v.18, p.57$106,1966$.

GRABLE, A.R.; SIEMER, E.F. Effects of bulk density, aggregate size and soil water suction on oxigen diffusion, redox potencials, and elongation of corn roots. Soil Sci Am. Proc., v.32, p.180-6, 1968.

HALE, M.G.; MOORE, L.D.; GRIFFIN, G.L. Root exudates and extracion. In: DOMMERGUES, Y.R.; KRUPA, S.V. (eds) Interaction between nonpathogenic soil microorganisms and plants. Amsterdam: Elsevier, 1978. cap 5, p. 163-203,.

HAN, G.E.; FREDERICK,L.R.; ANDERSON, J.C. Serological groups of japonicum in soybean nodules sampled in Iowa. Agronomy Journal, v.63, p.69-72, 1971.

HUNGRIA, M.; VARGAS, M.A.T; SUHET, A. R.; PERES, J.R.R. Fixação biológica de nitrogênio em soja. In: ARAUJO, R.S.; HUNGRIA, M. Microorganismo de Importância Agrícola. Brasilia: EMBRAPA-SPI, 1994.cap.2, p.9-89.

JOHNSON, H.W.; MEANS, V.M.; WEBER, C.R, Competition for nodule sites between strains of Rhizobium japonicum applied as inoculum and strains in the soil. Agron. J.,v.57, p.179-85, 1965. 
LOPES, A.S. Solos sob "cerrado", Características, propriedades e manejo. Piracicaba: Instituto Internacional da Potassa, 1984. 162p.

LOVATO, P.E.; PEREIRA,J.C.; VIDOR, C. Flutuação populacional de Rhizobium phaseoli em solos com e sem calagem. R. bras. Ci Solo, v.9(1), p.9-12, 1985.

MACEDO, J. Os cerrados nos ambientes savânicos do Brasi. In: VENEGAS, V.H.A.: FONTES, L.E.F.; FONTES, M.P.F. O solo nos grandes domínios morfoclimáticos do Brasil e o desenvolvimento sustentado. Viçosa: SBCS/UFV/DPS, 1996. p.135155 .

MALAVOLTA, E. Nutrição e adubação. I Simpósio brasileiro de feijão. Campinas, 1972. Anais. p. 211-242.

MARCOS FILHO, J. Produção de sementes de soja. Campinas: Fundação Cargill, 1986. $86 \mathrm{p}$.

MELO FILHO, J.F.; SILVA, J.R.C. Erosão, teor de água no solo e produtividade de milho em plantio direto e preparo convencional de um podzólico vermelho-amarelo no Ceará. R. bras. Ci. Solo, Campinas, v.17, p.291-297, 1993.

MEADE, J.; HIGGIN, P.; O'GARA, F. Studies on the inoculation and competitiveness of a Rhizobium loguminosarum strain in soils containing indigenous rizobia. Appl. Environ. Microbiol., v.49, p.899-903, 1985.

MOOTS, C.K.; NICKELL, C.D.; GRAY, L.E. Effects of soil compaction on the incidence of Phytophora megasperma f. Sp. Glycinea in soybean. Plant Dis., St. Paul, v.72, p.896-900, 1988.

MUNNS, D.N. Soil acidity and growth of a legume. I Interaction of lime with nitrogen and phosphate on growth of Medicago sativa (L.) and Trifolium subterraneum (L.) Aust. J. Agric. Res., v.16, p.733-741, 1965.

MUNNS, D.N. Soil acidity related factores. In: J.M. VINCENT; A.S. WHITNEY and J.BOSE (eds). Exploiting the legume - Rhizobium symbiosis in tropical 
agriculutre. Hawaii: Univ. Hawaii, Coll. Trop. Agric. Misc. Pulbl., , 1977. p. 21136.

NORRIS, D.O. Acid productions by Rhyzobium - a unifying concept. Plant Soil, v.22, p.143-66, 1965.

NUIERNBERG, N.J. Efeito de sucessões de culturas e tipos de adubação no rendimento e características de um solo na encosta basáltica sul-rio-grandense. Porto Alegre , 1983. 146p.Tese (Doutorado) -Faculdade de Agronomia da Universidade Federal do Rio Grande do Sul.

PERES, J.R.R.; VARGAS, M.A.T.; SUHET, A.R. Variabilidade na eficiência em fixar nitrogênio entre isolados de uma mesma estirpe de Rhizobium japonicum. R. bras. Ci Solo, v. 8, p. 193-196, 1984.

PERES, J.R.R.; VIDOR, C. Seleção de estirpes de Rhizobium japonicum e competividade por sítios de infecção nodular em cultivares de soja (Glycine max (L.) Merrill). Agron. Sulriog, v.16, p.205-19, 1980.

PHILLIPS, R.E.; KIRKHAN, A. Mechanical impedance and corn seedling root growth. Soil Science Society American Proceedings, v.26, p.319-22, 1962.

PIMENTEL, G.B.M.; CHAVES, R.S. Produtividde do caupi sob diferentes sistemas de manejo de um solo de várzea do Médio Amazonas Paraense. R. bras. Ci. Solo, Campinas, v.17, n.1, p.135-138, 1993.

RAIJ, B. Van; SILVA, N.M.da; BATATAGLIA, O.C. Recomendações de adubação e calagem para o estado de São Paulo. Campinas: Instituto Agronomico, 1985. 107p.

REICHERT, J.M.; VEIGA, M. da; CABEDA, M.S.V. Índices de estabilidade de agregados e suas relações com caracteristicas e parâmetros de solo. R. bras. Ci. Solo, Campinas, v.17, p.283-290, 1993.

ROSEMBERG, N.J. Response of plants to physical effects of soil compaction. Advances in Agronomy, v. 16, p.181-96, 1964. 
RUSCHEL, A. P.; SAITO, S. M. T. Efeito da inoculação de RHIZOBIUM, nitrogênio e matéria orgânica na fixação simbiótica de nitrogênio em feijão (Phaseolus vulgaris, L.). Rev. bras. ci. Solo, v.1, p.21-24, 1977.

SANCHEZ, P.A. Suelos del trópicos: cracteristica y manejo. San Jose: Inst. Interam. Coop. Agric. 1981.633p.

SPRENT, J.I. Nitrogen fixation by legumes subjected to water and light stress. In: NUTMAN, P.S. (ed) Symbiotic nitrogen fixation. Cambridge, Univ. Press, 1976, p. 505-20.

STONE, L.F. SILVIERIA, P.M.; ZIMMERMANN, F.J.P. Caracteristicas fisico-hídricas e químicas de um latossolo após adubacão e cultivos sucessivos de arroz e feijão, sob irrigação por aspersão. R. bras. Ci. Solo, Campinas, v. 18, 533-539, 1994.

SUMNER, M.E. Uso atual do gesso no mundo em solo ácidos. IN: II SEMINÁRIO SOBRE O USO DO GESSO NA AGRICULTURA,2., Uberaba, 1992. Brasília, Ed. Nagy, 1992. p.7-40.

TAYLOR, H.M.; GARDNER, H.R. Penetration of cotton seedling roots as influenced by bulk density, moisture content, and strenght of soil. Soil Sci., v.96, p.153-156, 1963.

TAYLOR, R.W.; WILLIAMS, M.L. SISTANI, K.R. $\mathrm{N}_{2}$ fixation by soybeanBradyrhizobium combinations under acidity, low $\mathrm{P}$ and high Al stresses. Plant Soil, v. 131, p.293-300, 1991.

TRIPLETT, E.W.; SADWSKY, M.J. Genetics of competition for nodulation of legumes.

Ann. Rev. Microbiol., v.45, p.399-429, 1992.

VARGAS, M.A.T.; MENDES, I.C. SUHET, A.R.; PERES, J.R.R. Duas novas estirpes de rizóbio para a inoculação da soja. Planaltina: EMBRAPA-CPAC, 1992. 3p. (Comunicado Técnico, 62)

VARGAS, M.A.T.; SUHET, A.R. Efeito de tipos e níveis de inoculantes na soja cultivada em solo de cerrado. Pesq. agropec. bras., v.15, p.343-47, 1980. 
VOMOCIL, J.A.; FLOCKER, W.J. Effect of soil,. compaction of storage and movement of soil air and water. Transaction of the ASAE, v.4, p.242-246, 1961.

VOORHEES, W. B. Soil compaction how it influences moisture, temperature, yield, root growth. Crops and Soil Magazine, v.29, p. 13-6, 1977 